Check for updates

Cite this: J. Mater. Chem. B, 2017, 5, 8799

\title{
Enhanced biostability and cellular uptake of zinc oxide nanocrystals shielded with a phospholipid bilayer
}

\author{
B. Dumontel, $\neq^{a}$ M. Canta, $\neq^{a} H$. Engelke, (D) ${ }^{b}$ A. Chiodoni, (D) ${ }^{c}$ L. Racca, ${ }^{a}$ A. Ancona, ${ }^{a}$ \\ T. Limongi, (D) ${ }^{a}$ G. Canavese (D) ${ }^{\text {ac }}$ and V. Cauda (D) *ac
}

\begin{abstract}
The widespread use of $\mathrm{ZnO}$ nanomaterials for biomedical applications, including therapeutic drug delivery or stimuli-responsive activation, as well as imaging, imposes a careful control over the colloidal stability and long-term behaviour of $\mathrm{ZnO}$ in biological media. Moreover, the effect of $\mathrm{ZnO}$ nanostructures on living cells, in particular cancer cells, is still under debate. This paper discusses the role of surface chemistry and charge of zinc oxide nanocrystals, of around $15 \mathrm{~nm}$ in size, which influence their behaviour in biological fluids and effect on cancer cells. In particular, we address this problem by modifying the surface of pristine $\mathrm{ZnO}$ nanocrystals (NCs), rich of hydroxyl groups, with positively charged amino-propyl chains or, more innovatively, by self-assembling a double-lipidic membrane, shielding the ZnO NCs. Our findings show that the prolonged immersion in simulated human plasma and in the cell culture medium leads to highly colloidally dispersed ZnO NCs only when coated by the lipidic bilayer. In contrast, the pristine and amine-functionalized NCs form huge aggregates after already one hour of immersion. Partial dissolution of these two samples into potentially cytotoxic $\mathrm{Zn}^{2+}$ cations takes place, together with the precipitation of phosphate and carbonate salts on the NCs' surface. When exposed to living HeLa cancer cells, higher amounts of lipid-shielded ZnO NCs are internalized with respect to the other samples, thus showing a reduced cytotoxicity, based on the same amount of internalized NCs. These results pave the way for the development of novel theranostic platforms based on $\mathrm{ZnO}$ NCs. The new formulation of $\mathrm{ZnO}$ shielded with a lipid-bilayer will prevent strong aggregation and premature degradation into toxic by-products, and promote a highly efficient cell uptake for further therapeutic or diagnostic functions.
\end{abstract}

Received 20th August 2017

Accepted 3rd October 2017

DOI: $10.1039 / \mathrm{c} 7 \mathrm{tb} 02229 \mathrm{~h}$

rsc.li/materials-b

\section{Introduction}

The use of zinc oxide ( $\mathrm{ZnO}$ ) based nanoplatforms in biomedical applications is constantly increasing over time, thanks to several useful therapeutic and diagnostic functions of $\mathrm{ZnO}^{1-6}$ Among them, photodynamic properties and rapid dissolution enhancing cytotoxicity or drug delivery were tested toward cancer cells, ${ }^{7}$ as well as green fluorescent emission strategies for bioimaging purposes. ${ }^{8}$ The current challenges for using $\mathrm{ZnO}$ as a theranostic tool include tailoring its nanoscale

\footnotetext{
${ }^{a}$ Department of Applied Science and Technology, Politecnico di Torino, Corso Duca degli Abruzzi 24, 10129 Turin, Italy. E-mail: valentina.cauda@polito.it

${ }^{b}$ Department of Chemistry, Ludwig-Maximilians-University of Munich, Butenandtstrasse 11E, 81377 Munich, Germany

${ }^{c}$ Center for Sustainable Future Technologies - CSFT@POLITO,

Istituto Italiano di Tecnologia, Corso Trento 21, 10129 Turin, Italy

$\dagger$ Electronic supplementary information (ESI) available. See DOI: 10.1039/ c7tb02229h

\# These authors contributed equally.
}

morphology, in terms of size, shape, ${ }^{9}$ aspect ratio, ${ }^{9-13}$ surface area $^{12}$ and most importantly its surface chemistry, ${ }^{14}$ to meet the desired biomedical application. For this reason, it is a prerequisite to have stable and colloidally dispersed $\mathrm{ZnO}$ in aqueous biological media. Actually, nano-sized and welldispersed particles should have dimensions comparable to naturally occurring biological molecules, allowing their internalization into cells ${ }^{15}$ and enabling them to act as bio-imaging tools or to potentially affect the cellular behaviour in a therapeutic perspective.

It has been largely demonstrated from in vivo experiments that the size and surface chemistry of nanoparticles govern their site of accumulation and action in living organisms. ${ }^{15}$ In the same way, it is known that the main cytotoxicity mechanisms of $\mathrm{ZnO}$ are related to the capability of the nanostructure to dissolve and to be internalized by cells. ${ }^{16,17}$ Since cell uptake is significantly influenced by the surface chemistry and size of $\mathrm{ZnO}$ nanoparticles, it turns out that the precise control of both parameters is fundamental. 
Concerning the surface chemistry, pristine $\mathrm{ZnO}$ nanoparticles' surface exposes neutral hydroxyl groups, which basically govern the surface charge behaviour. ${ }^{13,18}$ In a high $\mathrm{pH}$ aqueous medium, the chemisorbed protons $\left(\mathrm{H}^{+}\right)$leave the NP's outer layer inducing a negatively charged surface with partially bonded oxygen atoms $\left(\mathrm{ZnO}^{-}\right)$. On the other side, for low $\mathrm{pH}$ values, protons from the medium are most likely transferred to the particle surface, leading to positively charged $\mathrm{ZnOH}^{+}{ }_{2}$ groups. ${ }^{19}$ $\mathrm{ZnO}$ nanoparticles, characterized by an isoelectric point around pH 9-10, have a positive surface charge ${ }^{20}$ under physiological conditions. Cancer cells usually have high negative membrane potentials due to the presence of anionic phospholipids, charged proteins and carbohydrates $^{21}$ on their outer plasma membrane. ${ }^{22,23}$ Therefore, electrostatic interactions with positively charged $\mathrm{ZnO}$ nanoparticles would be expected to enhance the uptake of $\mathrm{ZnO}$ nanoparticles into tumor cells, thus affecting their viability. ${ }^{24}$

Charge and surface chemistry influence also the colloidal stability of nanoparticles, a crucial property for their interaction with biological systems. The presence of capping agents or coatings enables a precise control in this regard. ${ }^{11}$ Different approaches were used to enhance biocompatibility and decrease nanoparticles' aggregation, based on polymeric coatings, such as polyethylene glycol (PEG), ${ }^{25}$ propylene glycol, ${ }^{10}$ poly- $N$ vinyl-2-pyrrolidone (PVP) and others. ${ }^{26}$ However, the literature has also shown the effect of some of these stabilizers on the cytotoxicity of $\mathrm{ZnO} \mathrm{NPs}^{27}$

In general, several mechanisms of ZnO NPs' cytotoxicity were proposed. Some of them include $\mathrm{ZnO}$ nanoparticles' internalization inducing reactive oxygen species (ROS) ${ }^{28,29}$ and DNA damage, ${ }^{14,30}$ zinc ion release due to nanoparticles' dissolution, ${ }^{31-35}$ and membrane dysfunction. ${ }^{25,36}$ Nevertheless, in most cases, it is unclear if $\mathrm{ZnO}$ dissolution occurs in the extracellular medium before cellular uptake or intracellularly after the internalization. Certain works indicate that the $\mathrm{ZnO}$ cytotoxicity is independent of the concentration of extracellular soluble $\mathrm{Zn}^{2+}$ in the culture medium $^{37-39}$ and that a direct particle-cell contact or internalization is required for cellular toxicity. ${ }^{40}$

In agreement with other authors, ${ }^{41}$ we believe that the poor accordance between the literature results derives from a lack of control of the synthetic process, together with a large uncertainty about the surface chemistry and charge, as well as the wide size distribution of the NPs. To address these issues, in the present paper we propose a systematic approach to study the $\mathrm{ZnO}$ colloidal stability and cytotoxicity as a function of different and controlled surface treatments. We designed three types of ZnO nanocrystals (NCs) with different surface charge densities and chemistries: (i) bare ZnO NCs rich in hydroxyl groups, (ii) amino-propyl surface-functionalized ZnO NCs aiming at a predominant positive surface charge, and (iii) lipid-coated ZnO NCs for improving colloidal and chemical stability in biological media. We studied and tuned the colloidal stability in terms of long-lasting well-dispersed ZnO NC suspensions in different simulated body fluids for both in vitro and in vivo applications. In particular, we tested the three types of ZnO NCs in the cell culture medium and in a buffered solution mimicking the inorganic composition of the human plasma.
We observed a profound effect of the ZnO NCs' surface properties on the cellular internalization and cytotoxicity profiles in in vitro cancer cells. Therefore, the precise control of $\mathrm{ZnO}$ nanoparticles' surface is crucial to customize and develop new opportunities in cancer diagnosis and therapies. In detail, we demonstrate that engineering the surface of ZnO NCs with a shielding lipidic bilayer leads to a profound enhancement of the colloidal and chemical stability in biological and simulated media. Moreover, these properties are related to a reduced cytotoxicity and to an appreciable enhancement of cellular internalization of this novel hybrid nanoconstruct.

Our results are therefore of paramount importance to further improve advanced nano-imaging solutions and to design alternative therapeutic plans through the use of ZnO NCs when administered to cancer cells.

\section{Experimental}

\section{Synthesis of $\mathrm{ZnO}$ nanocrystals}

Pristine zinc oxide nanocrystals (ZnO NCs) were synthetized by a wet chemical method using zinc acetate dihydrate $\left(\mathrm{Zn}\left(\mathrm{CH}_{3} \mathrm{COO}\right)_{2} \cdot \mathrm{H}_{2} \mathrm{O}\right)$ and sodium hydroxide $(\mathrm{NaOH})$ as precursors and methanol as a solvent. In detail, $0.818 \mathrm{~g}(3.73 \mathrm{mmol})$ of $\mathrm{Zn}\left(\mathrm{CH}_{3} \mathrm{COO}\right)_{2} \cdot \mathrm{H}_{2} \mathrm{O}$ was dissolved in $42 \mathrm{~mL}$ of methanol in a $100 \mathrm{~mL}$ round bottom flask and heated to $60{ }^{\circ} \mathrm{C}$ under vigorous stirring. When the temperature reached $60{ }^{\circ} \mathrm{C}, 318 \mu \mathrm{L}$ of bi-distilled water (from a Direct Q3 system, Millipore) and a solution of $0.289 \mathrm{~g}(7.22 \mathrm{mmol})$ of $\mathrm{NaOH}$ in $23 \mathrm{~mL}$ of methanol were dropwise added to the zinc acetate solution. The resulting synthesis mixture was maintained, under continuous stirring, at $60{ }^{\circ} \mathrm{C}$ for $2.15 \mathrm{~h}$ and then washed two times with fresh ethanol using a repeated centrifugation-redispersion process.

\section{Preparation of $\mathrm{ZnO}-\mathrm{NH}_{2}$ nanocrystals}

The amino-propyl functionalized sample ( $\mathrm{ZnO}-\mathrm{NH}_{2} \mathrm{NCs}$ ) was obtained by the reaction of pristine zinc oxide nanocrystals and 3-aminopropyltrimethoxysilane (APTMS) as follows: $100 \mathrm{mg}$ $(1.23 \mathrm{mmol})$ of $\mathrm{ZnO} \mathrm{NCs}$, dispersed in ethanol, was heated to $78{ }^{\circ} \mathrm{C}$ in a $100 \mathrm{~mL}$ flask under continuous stirring and a nitrogen gas flow. After about 15 minutes, 21.4 $\mu \mathrm{L}$ of APTMS was added to the solution; this volume of the functionalizing agent corresponds to $0.123 \mathrm{mmol}(22.05 \mathrm{~g}$ ), equal to $10 \mathrm{~mol} \%$ of total $\mathrm{ZnO}$ amount. The obtained mixture was refluxed under a nitrogen gas flow for $6 \mathrm{~h}$ and then washed two times to remove the unbound APTMS molecules.

\section{Preparation of ZnO-DOPC nanocrystals}

To prepare lipid-coated nanocrystals (ZnO-DOPC NCs), a solvent exchange method was used. $2.5 \mathrm{mg}$ of DOPC (1,2-dioleoyl$s n$-glycero-3-phosphocholine) in chloroform was dried under vacuum overnight and re-dispersed in a $1 \mathrm{~mL}$ mixture of 40 vol\% ethanol and 60 vol\% bi-distilled water. Afterwards, a volume corresponding to $1 \mathrm{mg}$ of $\mathrm{ZnO}$ NCs was centrifuged, in order to remove all the ethanol, and then the pellet was suspended in $100 \mu \mathrm{L}$ of lipid solution. The addition of water 
$(700 \mu \mathrm{L})$ results in the formation of a supported lipid bilayer on the surface of ZnO NCs. The obtained ZnO-DOPC NCs were washed with water two times to remove the unbound lipids. For the bio-stability assays, the whole procedure was scaled-up to obtain $100 \mathrm{mg}$ of ZnO-DOPC NCs. For lipid-coated nanocrystals used in the fluorescence experiments, two labelling steps were added: liposomes were labeled with Bodipy-FL-DHPE by adding $0.5 \mu \mathrm{g}$ of fluorescent dye at $2.5 \mathrm{mg}$ of lipids before evaporating the chloroform. Amino-propyl functionalized nanocrystals (ZnO- $\mathrm{NH}_{2}$ NCs) were coupled with ATTO550-NHS ester dye, at a ratio of $2 \mu \mathrm{g}$ per $\mathrm{mg}$ of NCs. The suspension of dye and $\mathrm{ZnO}-\mathrm{NH}_{2}$ NCs in ethanol was kept in the dark under continuous stirring overnight and then the sample was washed two times with fresh ethanol in order to remove the unbound dye molecules.

\section{Bio-stability assays}

For the bio-stability assays, the three types of $\mathrm{ZnO}$ nanocrystals were tested in Simulated Body Fluid (SBF), and cell culture medium (EMEM) completed with $10 \%$ of fetal bovine serum.

To prepare the SBF, the following reagents were dissolved in $500 \mathrm{~mL}$ of bi-distilled water: $7.996 \mathrm{~g} \mathrm{NaCl}, 0.350 \mathrm{~g} \mathrm{NaHCO}_{3}$, $0.224 \mathrm{~g} \mathrm{KCl}, 0.228 \mathrm{~g} \mathrm{~K}_{2} \mathrm{HPO}_{4} \cdot 3 \mathrm{H}_{2} \mathrm{O}, 0.305 \mathrm{~g} \mathrm{MgCl}_{2} \cdot 6 \mathrm{H}_{2} \mathrm{O}$, $0.278 \mathrm{~g} \mathrm{CaCl}_{2}, 0.071 \mathrm{~g} \mathrm{Na}_{2} \mathrm{SO}_{4}, 40 \mathrm{~mL} \mathrm{HCl} 1 \mathrm{M}$, and $6.057 \mathrm{~g}$ $\mathrm{NH}_{2} \mathrm{C}\left(\mathrm{CH}_{2} \mathrm{OH}\right)_{3}$ (TRIS). The $\mathrm{pH}$ of the solution was then regulated at 7.4 at $37{ }^{\circ} \mathrm{C}$ and the solution was made up to $1.0 \mathrm{~L}$ and stored at $4{ }^{\circ} \mathrm{C}$ until use.

The bio-stability tests were performed at a concentration of $2 \mathrm{mg} \mathrm{mL}{ }^{-1}$, by suspending $25 \mathrm{mg}$ of each $\mathrm{ZnO} \mathrm{NC}$ sample (opportunely separated from ethanol or water with a centrifugation and washing step) in $12.5 \mathrm{~mL}$ of SBF or EMEM pre-heated at $37{ }^{\circ} \mathrm{C}$. The samples were maintained under continuous stirring $(150 \mathrm{rpm})$ at a constant temperature of $37{ }^{\circ} \mathrm{C}$. At selected times (1, 24, $72 \mathrm{~h}$ and 25 days), $2.5 \mathrm{~mL}$ of the suspension was collected and centrifuged. The supernatant was collected and opportunely diluted for ICP-MS analysis, whereas the ZnO NCs were washed with bi-distilled water twice and characterized.

\section{Physico-chemical characterization}

The particle size and Zeta potential of the three samples were determined using dynamic light scattering (Zetasizer Nano ZS90, Malvern). DLS measurements were performed by suspending $500 \mu \mathrm{g}$ of nanoparticles in $1 \mathrm{~mL}$ of various tested media (ethanol, water, SBF or EMEM). Zeta potential measurements were performed in bi-distilled water and the $\mathrm{pH}$ was adjusted with $\mathrm{HCl}$ and $\mathrm{NaOH} 1 \mathrm{M}$.

The morphology of the nanocrystals was studied by Field Emission Scanning Electron Microscopy (FESEM, Auriga and Merlin, Karl Zeiss) and Transmission Electron Microscopy (TEM, Tecnai F20ST, FEI) before and after the bio-stability assays. The samples were prepared by diluting $5 \mu \mathrm{L}$ of nanocrystals' suspension in bi-distilled water (final concentration $25 \mu \mathrm{g} \mathrm{mL}^{-1}$ ) and drying a drop of the resulting suspension on a silica wafer or on a holey carbon-coated copper grid for FESEM and TEM, respectively.
Fourier transform infrared spectra (FT-IR, recorded in transmission mode with a Bruker Equinox 55 in the region of 4000-400 $\mathrm{cm}^{-1}$ ) and energy dispersive spectra (EDS, Oxford Instruments, coupled to the FESEM Merlin, Karl Zeiss) were recorded in order to verify the success of functionalization procedures and to establish the precipitation of organic and inorganic compounds and their nature during bio-stability assays.

The formation of the supported lipid bilayer on the surface of ZnO-DOPC samples was also confirmed by fluorescence co-localization experiments. A fully motorized wide-field inverted microscope (Eclipse TiE from Nikon) equipped with a high resolution sCMOS camera (Zyla 4.2 Plus from Andor) was used with an immersion-oil $60 \times$ objective.

The crystalline structure of the material was analysed by $\mathrm{X}$-ray diffraction using an X'Pert diffractometer with $\theta-2 \theta$ BraggBrentano configuration using $\mathrm{Cu}-\mathrm{K} \alpha$ radiation $(\lambda=1.54 \AA$, $40 \mathrm{kV}$ and $30 \mathrm{~mA})$. The spectra were collected in the range of $20-60^{\circ}$ after each bio-stability assay step, in order to verify the preservation of nanoparticles' crystalline structure and the presence of crystalline precipitates.

\section{Internalization experiments in HeLa cells}

For cell experiments, HeLa cells (ATCC ${ }^{\circledR}$ CCL-2) were cultivated in DMEM supplemented with 10 vol\% FBS and 1 vol\% PenStrep. All reagents were purchased from Sigma-Merck.

The day before particle incubation the cells were seeded onto 8-well ibiTreat slides (Ibidi) at a concentration of 5000 cells per well containing $300 \mu \mathrm{L}$ of medium. They were incubated with the NCs at a final concentration of $18 \mu \mathrm{g} \mathrm{mL}{ }^{-1}$ for 24, 48 and $72 \mathrm{~h}$. NCs were prepared and labelled as described above, only replacing Atto550 by Atto633 NHS ester dye. After incubation for $24-72 \mathrm{~h}$, the cell membrane was stained immediately before imaging using WGA488 (Thermofisher Scientific) and washed with the medium after an incubation period of about 1 minute. Cells and particles were imaged at $37{ }^{\circ} \mathrm{C}$ under a $5 \% \mathrm{CO}_{2}$ humidified atmosphere using spinning disc microscopy (Zeiss Cell Observer SD utilizing a Yokogawa spinning disk unit CSU-X1). The objective was a 1.40 NA $63 \times$ Plan apochromat oil immersion objective (Zeiss). Atto633 was imaged with $639 \mathrm{~nm}$ and WGA488 with $488 \mathrm{~nm}$ laser excitation. For two colour detection a dichroic mirror (560 nm, Semrock) and band-pass filters 525/50 and 690/60 (both Semrock) were used in the detection path. Separate images for each fluorescence channel were acquired using two separate electron multiplier charge coupled device (EMCCD) cameras (Photometrics Evolve TM).

The stacks of confocal fluorescence images of cells interacting with nanoparticles were analysed applying the Particle_in_ Cell-3D plugin based on the ImageJ software and free to download at the ImageJ Documentation Portal. ${ }^{42}$ For each experimental condition, 13 cells were randomly selected from the confocal z-stacks and independently analysed. The fluorescence image of the cell membrane in each confocal plane was transformed into a 3D mask of the cell. 
By applying this mask to the corresponding particle fluorescence images, intra- and extra-cellular nanoparticles were automatically discriminated. To get a semiquantitative result, for each cell the sum of all pixel intensities corresponding to the intracellular nanoparticle fluorescence signal was finally calculated and then averaged over all cells corresponding to the same experimental condition. The fluorescence intensity threshold of nanoparticles was kept constant for all the stacks.

\section{Cytotoxicity experiments}

HeLa cells were seeded at a concentration of 5000 cells per well into 96 well plates (Corning) containing a final volume of $100 \mu \mathrm{L}$ of medium. One day after seeding they were incubated with NCs at the desired concentration. $72 \mathrm{~h}$ after incubation with NCs, MTT tests were performed according to the standard protocol.

\section{Results and discussion}

\section{Zinc oxide nanocrystals}

For this study, we selected a wet chemical route for obtaining small ZnO nanocrystals (ZnO NCs) with a spherical shape, as reported in detail in the Experimental section. A fast synthetic approach, modified from that already reported in the literature, ${ }^{43}$ was applied involving zinc acetate dihydrate and sodium hydroxide in a molar ratio $\mathrm{Zn}^{2+}: \mathrm{OH}^{-}$of $1: 1.94$ and in polar methanol solvent at mild temperature $\left(60{ }^{\circ} \mathrm{C}\right)$ according to the following chemical reactions:

$$
\mathrm{Zn}^{2+}+2 \mathrm{OH}^{-} \rightarrow \mathrm{Zn}(\mathrm{OH})_{2}
$$

$$
\begin{gathered}
\mathrm{Zn}(\mathrm{OH})_{2}+2 \mathrm{OH}^{-} \rightarrow \mathrm{Zn}(\mathrm{OH})_{4}{ }^{2-} \\
\mathrm{Zn}(\mathrm{OH})_{4}{ }^{2-} \rightarrow \mathrm{ZnO}+\mathrm{H}_{2} \mathrm{O}+2 \mathrm{OH}^{-}
\end{gathered}
$$

We obtained spherical shaped, well-dispersed nanocrystals having a size of about $14 \mathrm{~nm}$ in diameter (Fig. 1a, measured from Field Emission Scanning Electron Microscopy (FESEM) with the application of a thin Pt conductive layer.). Both Transmission Electron Microscopy (TEM) and Scanning Transmission Electron Microscopy (STEM) also confirmed the round shape of the ZnO NCs and their size (Fig. 1a). The literature indicates indeed to maintain the $\mathrm{Zn}^{2+}: \mathrm{OH}^{-}$molar ratio between $1: 1.6$ and $1: 1.95$ to obtain $\mathrm{ZnO}$ particles with a diameter below $15 \mathrm{~nm}$. The X-ray diffraction pattern (Fig. S1 in the ESI $\dagger$ ) shows that the ZnO NCs are in the single-phase wurtzite crystalline structure (according to the JCPDS 36-1451, hexagonal, space group $P 63 \mathrm{mc}$ ). The Debye-Scherrer equation applied to the broad diffraction peaks confirms the average size of nanocrystallites, being around $15 \mathrm{~nm}$. After functionalization with either aminopropyl groups $\left(\mathrm{ZnO}-\mathrm{NH}_{2}\right.$ in Fig. $\left.1 \mathrm{~b}\right)$ or the lipid layer (ZnO-DOPC in Fig. 1c), the morphology and the crystalline structure of the NCs are not modified (Fig. S1 in the ESI $\dagger$ ), except in the size of the ZnO-DOPC sample, which presents larger particles of around $20 \mathrm{~nm}$.

We can suppose the formation of a supported lipid bilayer of a few $\mathrm{nm}$ in thickness on the surface of ZnO NCs, as previously reported by some of us using the solvent-exchange methods applied to a lipid solution in the presence of mesoporous silica nanoparticles. ${ }^{44}$ The approach relies on the effects that a (a) $\mathrm{ZnO}$

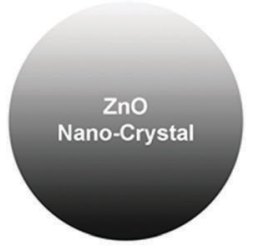

(b) $\mathrm{ZnO}-\mathrm{NH}_{2}$

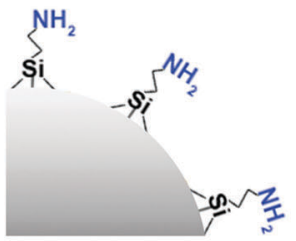

(c) ZnO-DOPC

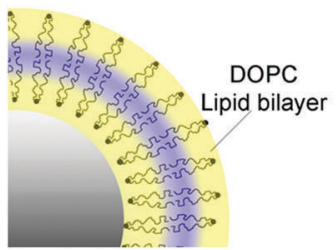

Fig. 1 The three $\mathrm{ZnO}$ nanocrystals used in this study: (a) pristine $\mathrm{ZnO} \mathrm{NCs}$, (b) amine-propyl functionalized $\mathrm{ZnO}-\mathrm{NH}_{2} \mathrm{NCs}$, and (c) lipid-coated ZnO-DOPC NCs. From left to right: scheme of the particles, FESEM, TEM and STEM images for each NC type. For FESEM images all the NCs were coated by a thin layer of Pt. The scale bar is $50 \mathrm{~nm}$ in all FESEM and TEM images, whereas it is $20 \mathrm{~nm}$ in all the three STEM images (right column). 
(a)

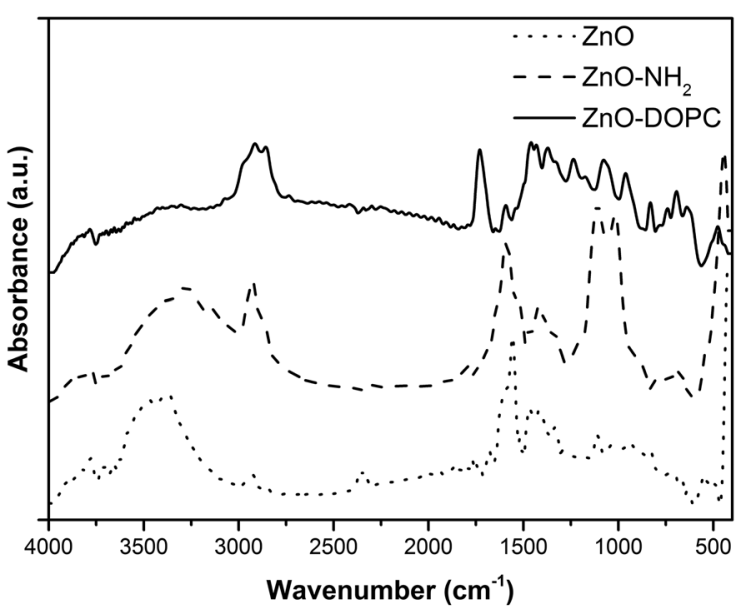

(b)

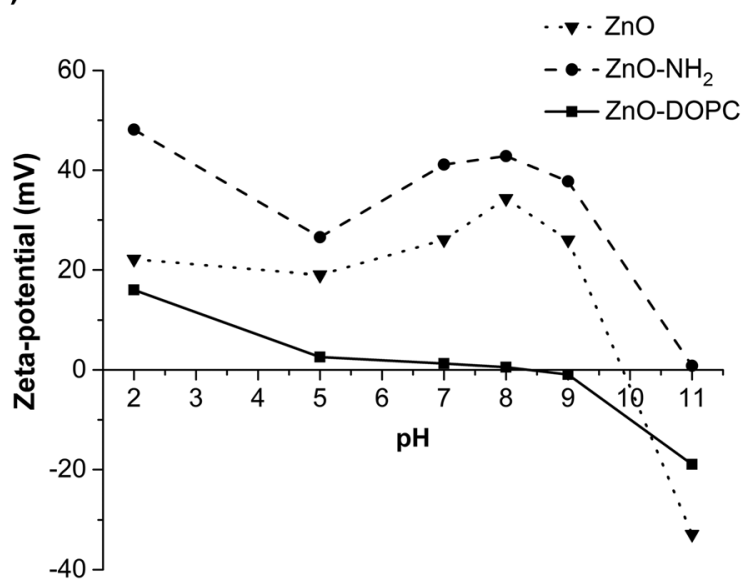

Fig. 2 (a) Fourier Transform-InfraRed (FT-IR) spectra and (b) Z-potential measurements of the pristine $\mathrm{ZnO}$ and functionalized $\mathrm{ZnO}-\mathrm{NH}_{2}$ and ZnO-DOPC NCs.

solvent has on the self-assembly behaviour of lipids. Since the interaction between lipid molecules and alcoholic solutions (ethanol or isopropanol) is favourable, the lipids are solvated and exist as monomers at low water concentrations. However, by adding water to the solution, the lipids begin to selfassemble into liposomes, constituted by a lipid bilayer. ${ }^{45}$ In this arrangement, the hydrophobic tails of the lipids are protected from water. A similar behaviour is observed in the presence of the surface of a nanoparticle, which offers a favourable support for the lipid bilayer self-assembly. ${ }^{44}$

The successful functionalization procedure of pristine $\mathrm{ZnO}$, leading to $\mathrm{ZnO}-\mathrm{NH}_{2}$ and $\mathrm{ZnO}-\mathrm{DOPC}$, is supported by both Fourier Transform-InfraRed (FT-IR) and $Z$-potential analyses. The FT-IR spectra (Fig. 2a) of $\mathrm{ZnO}$ and $\mathrm{ZnO}-\mathrm{NH}_{2}$ nanocrystals show in general some common features among the two different $\mathrm{ZnO}$ samples, such as an intense mode at $440 \mathrm{~cm}^{-1}$ typical of $\mathrm{Zn}-\mathrm{O}$ vibration and a broad band from 3600 to $3200 \mathrm{~cm}^{-1}$, which is due to the stretching vibration of hydroxyl groups on the $\mathrm{ZnO}$ surface. In addition, the two spectra show with different intensities the $\mathrm{C}=\mathrm{O}$ and $\mathrm{C}-\mathrm{O}$ vibration modes at 1570 and $1420 \mathrm{~cm}^{-1}$, as well as the symmetric and antisymmetric stretching of $-\mathrm{CH}_{2}$ and $-\mathrm{CH}_{3}$ groups at 2860 and $2925 \mathrm{~cm}^{-1}$, respectively. These vibrations are attributed to residual acetate groups on the $\mathrm{ZnO}$ surface due to the precursors used or to methoxy groups derived from the reflux conditions, used in the synthetic procedure. ${ }^{46}$ However, in the case of $\mathrm{ZnO}-\mathrm{NH}_{2} \mathrm{NCs}$, the 2860 and $2925 \mathrm{~cm}^{-1}$ stretching modes are more intense because of the presence of the propyl chain of the aminefunctional group, thus confirming the successful functionalization of the $\mathrm{ZnO}$ surface. The $\mathrm{ZnO}-\mathrm{NH}_{2} \mathrm{NCs}$ ' spectrum also shows an absorption peak near $3200 \mathrm{~cm}^{-1}$, characteristic of primary amines, and new bands at 1020 and $1100 \mathrm{~cm}^{-1}$, corresponding to the symmetric and asymmetric stretching of the O-Si-O groups, respectively, present in the aminopropyl-trimethoxysilane (APTMS) chain. Moreover, the band at $3800 \mathrm{~cm}^{-1}$ and the one from 3600 to $3400 \mathrm{~cm}^{-1}$, due to the stretching vibrations of hydroxyl groups on the $\mathrm{ZnO}$ surface, are less pronounced in the $\mathrm{ZnO}-\mathrm{NH}_{2}$ sample with respect to the pristine ZnO. Since the APTMS moiety links through hydroxyl groups to the oxide surface $(\mathrm{Zn}-\mathrm{OH})$, leading to $\mathrm{Zn}-\mathrm{O}-\mathrm{SiR}$ bonds, the above-mentioned-observation further confirms the successful amine functionalization of our ZnO NCs.

The formation of a phospholipidic layer on the $\mathrm{ZnO}$ surface was confirmed by the presence of intense peaks at 2860, 2925 and $1750 \mathrm{~cm}^{-1}$ in the ZnO-DOPC spectrum. These peaks are assigned to the stretching vibrations of $-\mathrm{CH}_{x}$ and $\mathrm{C}=\mathrm{O}$ groups, respectively, present in the phospholipid hydrophobic tails. Moreover, the characteristic stretching of $\mathrm{P}=\mathrm{O}$ and $\mathrm{P}-\mathrm{O}$ appeared at 1100 and $1230 \mathrm{~cm}^{-1}$. The disappearance of the -OH broad band from 3600 to $3200 \mathrm{~cm}^{-1}$ and the attenuation of the $\mathrm{Zn}-\mathrm{O}$ bond vibration peak at $440 \mathrm{~cm}^{-1}$ further confirm the success of $\mathrm{ZnO}$ interaction with DOPC molecules.

The Z-potential (Fig. 2b) of the three samples was evaluated in water at different $\mathrm{pH}$ values, obtaining different behaviour and isoelectric points (IEP) depending on the surface properties of the ZnO NCs and thus on the surface functionalization. For pristine $\mathrm{ZnO}$, the hydroxyl groups at the surface can protonate at acidic $\mathrm{pH}$, forming $\mathrm{ZnOH}_{2}{ }^{+}$species, whereas at highly basic $\mathrm{pH}, \mathrm{ZnO}^{-}$species are formed. ${ }^{20}$ The measured isoelectric point (IEP) for pristine $\mathrm{ZnO}$ is at $\mathrm{pH} 9.85$, in good agreement with the literature values. ${ }^{20}$ Therefore, at lower $\mathrm{pH}$, and in particular at neutral $\mathrm{pH}$, interesting for biological applications, the pristine ZnO NCs show a positive $Z$-potential.

Higher positive values of $Z$-potential are even observed for the $\mathrm{ZnO}-\mathrm{NH}_{2}$ NCs: actually, at acidic $\mathrm{pH}$ the amine groups at the $\mathrm{ZnO}$ surface can protonate, forming $-\mathrm{NH}_{3}{ }^{+}$species and the IEP of these amine-functionalized NCs is shifted to $\mathrm{pH}$ 11. In contrast, an important shift to lower $Z$-potential values is obtained for the ZnO-DOPC sample, having an IEP at pH 7.8. The DOPC phospholipid, showing both a negative phosphate and a positive amine head group (see the molecule scheme in Fig. S2 of the ESI $\dagger$ ), neutralizes the surface charge of $\mathrm{ZnO}$ and flattens its $Z$-potential behaviour, with slightly positive values at acidic $\mathrm{pH}$ and slightly negative values at basic $\mathrm{pH}$. The comparison of the $Z$-potential behaviour of $\mathrm{ZnO}-\mathrm{NH}_{2}$ and $\mathrm{ZnO}-\mathrm{DOPC}$ with that of pristine $\mathrm{ZnO}$ gives a clear confirmation that both chemical functionalization and coverage by phospholipids of ZnO NCs worked successfully. 

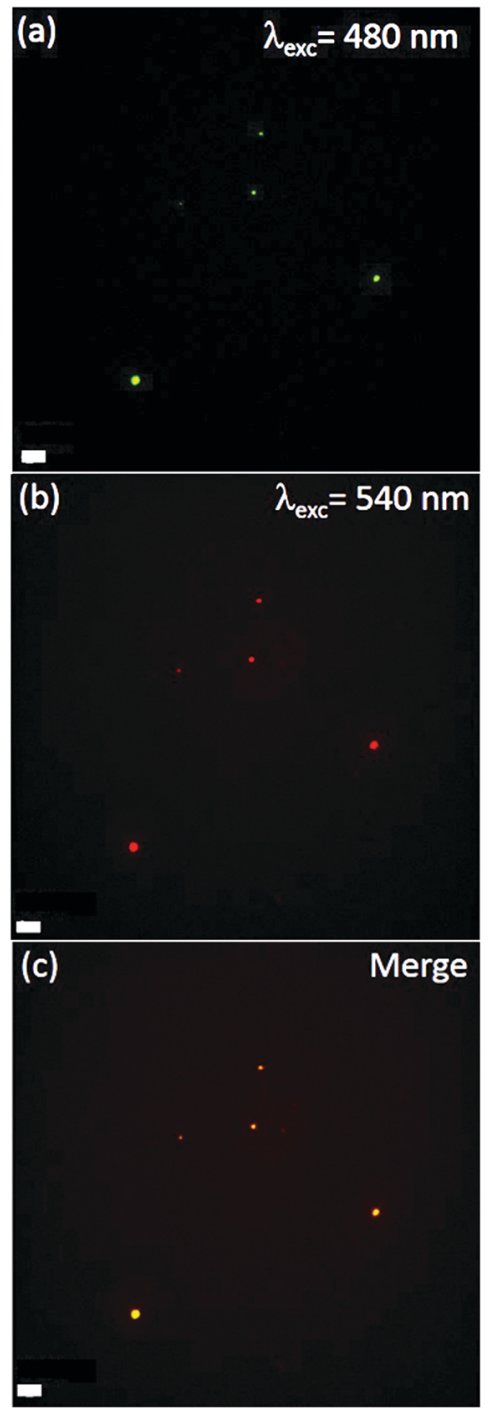

Fig. 3 Wide-field fluorescence image of the (a) lipid shell labeled by $1 \%$ Bodipy-DHPE; (b) ZnO-NH 2 NCs conjugated with Atto550-NHS ester; and (c) the merged channels showing complete co-localization. Scale bar: $10 \mu \mathrm{m}$.

It is worth mentioning that, since $\mathrm{ZnO}$ is prone to degradation at acidic $\mathrm{pH}$, here every measurement at each $\mathrm{pH}$ value was followed by a DLS check, still showing a good count rate and detecting the presence of the nanocrystals.

Further evidence of the lipid bilayer formation of the $\mathrm{ZnO}$ NCs is obtained by fluorescence microscopy co-localization experiments in wide-field configuration (Fig. 3). The DOPC lipid formulation was conjugated with 1\% Bodipy-DHPE lipid, showing fluorescence excitation at around $488 \mathrm{~nm}$ (Fig. 3a). Additionally, ZnO NCs functionalized with amino-propyl groups can be efficiently coupled with Atto550-NHS ester dye, having fluorescence excitation at $550 \mathrm{~nm}$ (Fig. 3b). By merging the two distinct images, it is worth noting that all the bright spots in both green and red channels co-localize in the same position (Fig. 3c and Fig. S3 in the ESI $\dagger$ ). Different experiments were carried out, showing a high percentage of red-labelled NCs

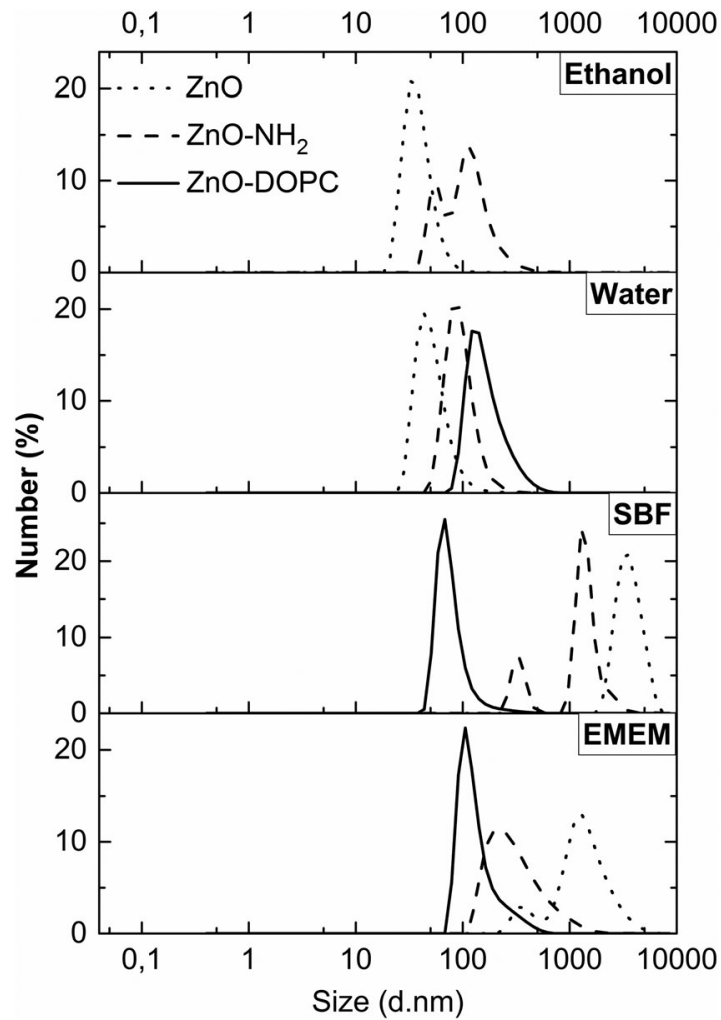

Fig. 4 Dynamic Light Scattering (DLS) measurements in number \% of the $\mathrm{ZnO}$ samples, pristine $\mathrm{ZnO} \mathrm{NCs}$ (dotted curves), $\mathrm{ZnO}-\mathrm{NH}_{2} \mathrm{NCs}$ (dashed curves), and ZnO-DOPC NCs (solid curves) in different media (ethanol, water, SBF, and EMEM).

co-localizing with the green-labelled lipids. The conjugation yield was evaluated to be $\mathbf{9 5 . 8 \%}$. In addition, since ZnO NCs can emit in the green channel when excited by UV-light, we have also imaged the ZnO NCs by exciting them at $340 \mathrm{~nm}$ and collecting their fluorescence in the blue channel (Fig. S3c in the $\mathrm{ESI} \dagger)$. We can actually co-localize in the same position the $\mathrm{ZnO}$ NCs' fluorescent emission together with the Atto550 dye in the red channel attached to the ZnO surface and the lipid shell in the green one, thus shielding the nanocrystals.

The EDS analysis for the three samples (reported in Table S3 of the $\mathrm{ESI}^{\dagger}$ ) shows that the samples are of $\mathrm{ZnO}$ material. In the case of ZnO-DOPC NCs, the presence of an increased amount of carbon and a small amount of phosphorus confirms the presence of lipids.

The colloidal stability of the three ZnO NCs was proven by DLS (Fig. 4), monitoring their behaviour in various media, primarily in ethanol and water solutions, then in the physiological simulated media (SBF) and in the cell culture medium (EMEM) completed with $10 \%$ of fetal bovine serum. The aim of using the last two solutions is to unravel the behaviour of $\mathrm{ZnO}$ NCs and the influence of surface charge and chemistry on the promotion of colloidal stability in both simulated and biological media. The SBF is an inorganic buffered salt solution simulating the composition of human plasma. The DLS behaviours versus time (as further shown in Fig. 5) would roughly simulate what could happen when the above mentioned 
(a)

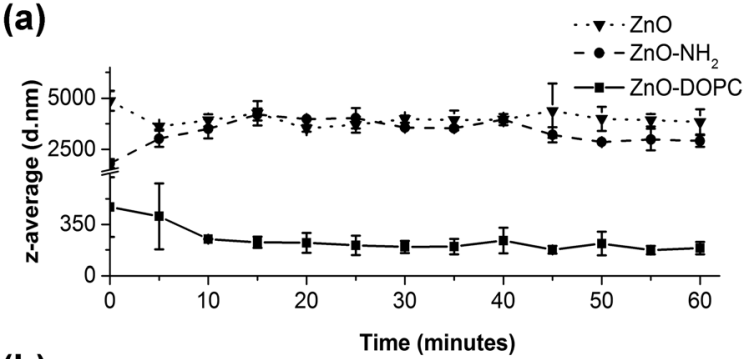

(b)

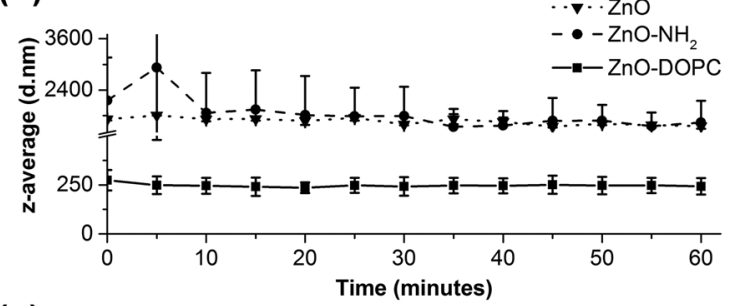

(c)

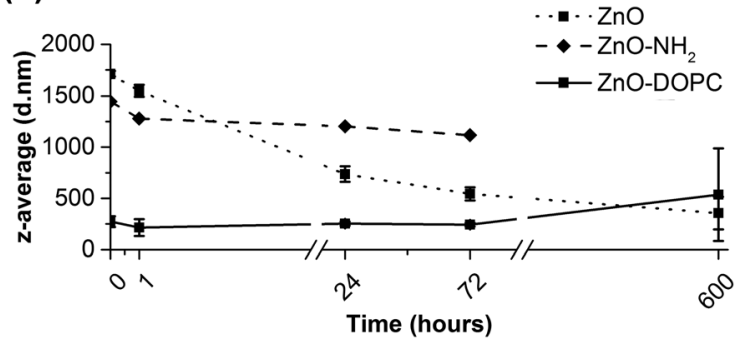

Fig. 5 DLS analysis comparing the behaviour of pristine ZnO NCs (dotted curve) and $\mathrm{ZnO}-\mathrm{DOPC}$ NCs (solid curve) in terms of mean hydrodynamic size ( $z$-average) in (a) SBF and (b) EMEM for both short (1 hour) and (c) long (25 days) time periods.

nanocrystals are in contact with plasma fluids, i.e. for a hypothetical injection into living systems for further therapy or diagnostic purposes. It is indeed of prominent importance to avoid aggregation in the bloodstream of nanoparticles conceived to have therapeutic or diagnostic effects on a pathological site of interest in the organisms. Moreover, an efficient cell uptake and thus therapeutic/diagnostic treatments can be achieved solely by having well-dispersed nanoparticles, i.e. in the cell culture medium (EMEM) for in vitro experiments.

Concerning the ZnO-DOPC NCs, the self-assembled lipid bilayers on the $\mathrm{ZnO}$ surface can be disassembled by the presence of alcoholic solutions; ${ }^{45}$ thus the DLS measurements were only carried out in water-based solutions (Fig. 4 from the second to the fourth panel). We observed that ZnO NCs are well dispersed in both EtOH (ZnO hydrodynamic diameter: $35 \mathrm{~nm}$ ) and water media (ZnO: $44 \mathrm{~nm}$ ). In contrast, the $\mathrm{ZnO}-\mathrm{NH}_{2} \mathrm{NCs}$ show aggregation in ethanol ( $\mathrm{ZnO}-\mathrm{NH}_{2}: 59$ and $\left.106 \mathrm{~nm}\right)$ and good dispersion in water solution $\left(\mathrm{ZnO}-\mathrm{NH}_{2}: 88 \mathrm{~nm}\right)$. It is also worth noting that the functional layers, both lipidic and aminemoieties, contribute to a larger hydrodynamic diameter of $\mathrm{ZnO}$ NCs in water solution (with ZnO-DOPC NCs' mean diameter of $122 \mathrm{~nm}$ ). In $\mathrm{SBF}, \mathrm{ZnO}$ and $\mathrm{ZnO}-\mathrm{NH}_{2}$ NCs form large aggregates of micrometer size, whereas ZnO-DOPC NCs remain highly colloidally dispersed (with a hydrodynamic diameter of $66 \mathrm{~nm}$ ). The improved $\mathrm{ZnO}-\mathrm{DOPC}$ colloidal stability is further confirmed in EMEM (a narrow hydrodynamic peak at $104 \mathrm{~nm}$ ). We attribute this colloidally stable behaviour to the lipid shell stabilization, shielding the ZnO NCs. In particular, the lipid coating limits the contact with the $\mathrm{ZnO}$ surface preventing possible interactions with solution's components. It is also worth noting that in EMEM also the $\mathrm{ZnO}-\mathrm{NH}_{2}$ NCs show a less extent of aggregation (215 nm) compared to pristine ZnO NCs (1255 nm)

\section{Biostability assays in simulated body fluid and cell culture media}

The previous DLS results showed that the lipid-coating provides a significant enhancement of colloidal stability in both SBF and EMEM fluids. Thus, to monitor this behaviour over time, we recorded in real-time the $z$-average (mean hydrodynamic diameter in $\mathrm{nm}$ weighed on the scattered light intensity from the ensemble collection of particles) of ZnO-DOPC NCs and their uncoated counterparts ( $\mathrm{ZnO} \mathrm{NCs}$ and $\mathrm{ZnO}-\mathrm{NH}_{2} \mathrm{NCs}$ ) in both SBF and EMEM over time (Fig. 5). It is worth mentioning that we also tried to record DLS analysis longer than 60 minutes in SBF; however further measurements did not meet the quality criteria due to the high instability of the $\mathrm{ZnO} \mathrm{NC}$ and $\mathrm{ZnO}-\mathrm{NH}_{2}$ $\mathrm{NC}$ samples in SBF for $t>60 \mathrm{~min}$. For consistency, the ZnO-DOPC NCs were not further measured. In contrast, we can report the data in EMEM also for long time periods for the three samples.

In Fig. 5a, the mean hydrodynamic size ( $z$-average) of the pristine ZnO NCs is relatively high, ranging from $3529 \mathrm{~nm}$ to $4870 \mathrm{~nm}$, meaning that this sample immediately forms huge aggregates when exposed to the SBF solution. A visual check was also performed, noting that pristine ZnO NCs form a white, fluffy precipitate at the bottom of the measurement cuvette almost immediately after contact with SBF. A similar behaviour was observed for the pristine $\mathrm{ZnO}$ within the first hour in EMEM, with $z$-average ranging from a minimum of 1600 to a maximum of $1850 \mathrm{~nm}$. Aggregation in both SBF and EMEM was recorded also for the $\mathrm{ZnO}-\mathrm{NH}_{2}$ NCs. In contrast, the $\mathrm{ZnO}-$ DOPC sample remained with a constant and small $z$-average (from a minimum value of $194 \mathrm{~nm}$ to a maximum of $314 \mathrm{~nm}$ ) in both SBF and EMEM solutions for the first hour of the experiments (Fig. 5a and b), accounting for a well-dispersed and stable sample. When analysing the data in EMEM for long periods (Fig. 5c) the $z$-average of $\mathrm{ZnO}-\mathrm{DOPC}$ maintains a constant value of about 200-300 $\mathrm{nm}$ for the first 72 hours, increasing up to $500 \mathrm{~nm}$ after 25 days. In contrast, the pristine ZnO NCs account for a decreasing $z$-average (starting from $1800 \mathrm{~nm}$ down to $360 \mathrm{~nm}$ ) accompanied by a decrease of the signal count rate, which corresponds to particle precipitation. The $\mathrm{ZnO}-\mathrm{NH}_{2}$ NCs show a constant value at around $1100 \mathrm{~nm}$, consisting of aggregated but still suspended particles.

FESEM analyses were performed on the three different NCs after selected time steps $(1 \mathrm{~h}, 72 \mathrm{~h}$, and 25 days $)$ of the biostability assays in both SBF and EMEM (Fig. 6 and Fig. S4, S5 in the ESI $\dagger$ ).

Both $\mathrm{ZnO}$ and $\mathrm{ZnO}-\mathrm{NH}_{2}$ NCs show strong aggregation already from the first hour, as confirmed by the previous DLS analysis. Both kinds of NCs tend to form spherical aggregates, 

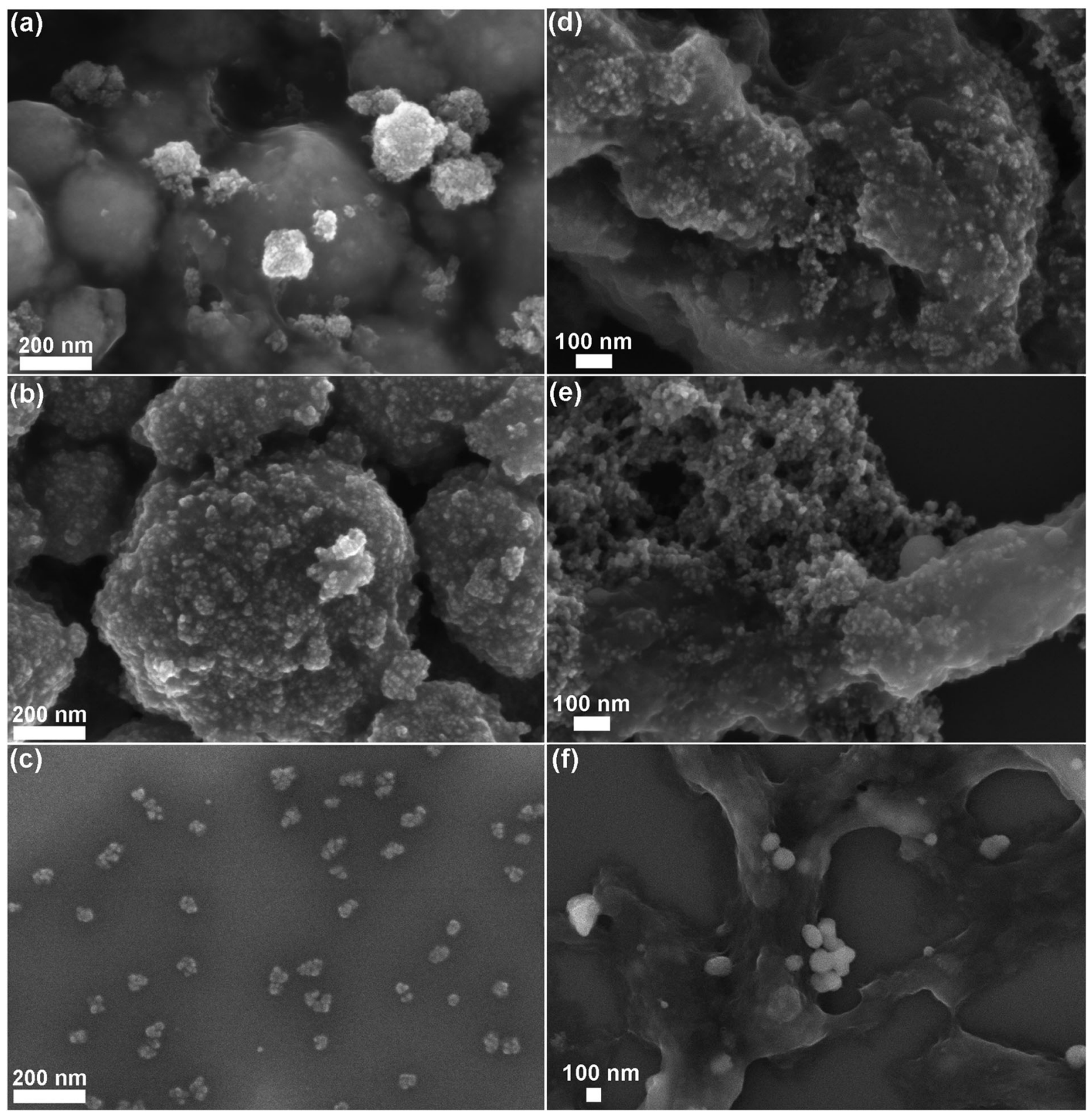

Fig. 6 FESEM images of the biostability behaviour of the three $\mathrm{ZnO}$ nanocrystals after 25 days assay times in SBF (left column) and EMEM (right column): (a-d) pristine $\mathrm{ZnO}$, (b-e) $\mathrm{ZnO}-\mathrm{NH}_{2}$, and (c-f) lipid-shell coated $\mathrm{ZnO}-\mathrm{DOPC}$.

whose dimension increases with time. The images of pristine ZnO NCs in both SBF and EMEM solutions after 1 and 72 hours still reveal the morphology of the single NCs (see the inset of Fig. S4a and S5a at the corresponding times in the ESI $\dagger$ ). In contrast, after 25 days in SBF (Fig. 6a and Fig. S4a bottom and related inset), the sample appears strongly aggregated and the single NCs are almost indistinguishable. This behaviour is also evident for ZnO NCs after 25 days in EMEM solution (Fig. 6d) in which the aggregates are constituted by a smooth matrix that seems to incorporate the nanocrystals.

Similar considerations can be applied for the $\mathrm{ZnO}-\mathrm{NH}_{2}$ samples, forming spherical micrometer-sized aggregates in SBF after 25 days (Fig. 6b). Large and compact clusters are formed in EMEM with the presence of precipitates, possibly derived from the solution (Fig. S5b in the ESI $\dagger$ after $72 \mathrm{~h}$ ), and a smooth matrix encapsulating the $\mathrm{ZnO}-\mathrm{NH}_{2} \mathrm{NCs}$ is visible for the long time step of 25 days (Fig. 6e).

In contrast with the previous results, the ZnO-DOPC NC sample shows well distinguishable round-shaped particles even after biodegradation tests. This behaviour is observed for all time points in both SBF (Fig. S4 in the ESI $\dagger$ ) and EMEM (Fig. S5 in the ESI $\dagger$ ). In particular, tiny and well-dispersed nanoparticles can be observed after 25 days in SBF (Fig. 6c) and until 72 hours in EMEM (Fig. S5c in the ESI $\dagger$ ). Formation of some aggregates for a longer time period, i.e. 25 days in EMEM (Fig. 6f), can be observed together with the presence of a soft matrix possibly 
derived from the medium. Strikingly, the well distinguishable ZnO-DOPC NCs observed in the FESEM analysis after $72 \mathrm{~h}$ and 25 days in both SBF and EMEM media are in fair agreement with the DLS data. In contrast, it is important to note that in both $\mathrm{ZnO}$ and $\mathrm{ZnO}-\mathrm{NH}_{2} \mathrm{NC}$ samples after 25 days, the nanocrystals are no longer distinguishable. In both cases, particle aggregation, fusion and dissolution occur, as demonstrated below with further characterization techniques.

The interaction between SBF and EMEM solutions and nanocrystal surfaces, already supposed when observing FESEM images, is confirmed by both FT-IR and EDS analyses which highlight the presence of more elements in addition to the forecasted $\mathrm{Zn}$ and $\mathrm{O}$.

EDS results (reported in Tables S3 and S4 along with SBF and EMEM compositions in Tables S1 and S2 of the ESI $\dagger$ ) show the presence of carbon, phosphorus, sodium, calcium and chlorine for all the three samples, i.e. $\mathrm{ZnO}, \mathrm{ZnO}-\mathrm{NH}_{2}$ and ZnO-DOPC NCs, at different biostability times in both SBF and EMEM. For samples in contact with EMEM, the presence of sulphur, potassium, magnesium and a higher content of carbon is detected, due to the high amount of proteins, amino acids and other biomolecules in the cell culture medium. These data confirm that the matrix incorporating the nanocrystals, in particular visible for the $\mathrm{ZnO}$ and $\mathrm{ZnO}-\mathrm{NH}_{2}$ samples in EMEM, is made of such biomolecules.

Further confirmations are given from FT-IR spectra (Fig. 7), which show increasing vibrational peaks in terms of frequency and intensity, with respect to the untreated NCs, at increasing times of biostability assays. It is, in particular, worth mentioning an increasing peak, in all the three kind of samples, at $1045 \mathrm{~cm}^{-1}$, ascribed to the stretching vibration of the $\mathrm{P}-\mathrm{O}$ bond. As also evidenced by EDS analysis, we assume that phosphate derivatives $\left(\mathrm{PO}_{4}{ }^{3-}\right)$ precipitate on these sample surfaces due to contact with either SBF or EMEM, both containing phosphate compounds. In particular, at long biostability times (i.e. 72 hours and 25 days), peaks at $1220 \mathrm{~cm}^{-1}$ and $1150 \mathrm{~cm}^{-1}$ appear, related to the stretching of $\mathrm{P}=\mathrm{O}$ bonds, again attributed to the phosphate groups. Stretching typical of carbonate groups (C-O) also appears, in accordance with the increase of carbon content revealed by EDS analysis.

Concerning the $\mathrm{ZnO}-\mathrm{DOPC}$, the presence of a phospholipid layer on the $\mathrm{ZnO}$ surface was already confirmed by the presence of peaks at $2860,2925 \mathrm{~cm}^{-1}$ (stretching vibrations of $-\mathrm{CH}_{x}$ ) and $1750 \mathrm{~cm}^{-1}(\mathrm{C}=\mathrm{O}$ groups $)$ that maintain a constant intensity at different biostability times in both SBF and EMEM solutions. Also in both $\mathrm{ZnO}$ and $\mathrm{ZnO}-\mathrm{NH}_{2}$ samples, the vibrations at 2955,2915 , and $2855 \mathrm{~cm}^{-1}$ related to the stretching of $-\mathrm{CH}_{2}$ and $-\mathrm{CH}_{3}$ groups are already present in the spectra of the untreated materials, as observed in Fig. 3a. However, longer biostability times in both SBF and EMEM produce an increase of these stretching peaks in both $\mathrm{ZnO}$ and $\mathrm{ZnO}-\mathrm{NH}_{2}$ NCs accompanied by a constant decrease of the hydroxyl stretching vibration $(-\mathrm{OH})$ between 3600 and $3000 \mathrm{~cm}^{-1}$. Here two different hypotheses could be made, depending on the solution composition. In SBF medium, we assume that the oxide surface of the NCs reacts with some components of the solution, in particular with TRIS (Tris(hydroxymethyl)aminomethane chlorohydrate), leading to partial hydrolysis and reaction with methyl groups of the buffer component, responsible for the increase of the $-\mathrm{CH}_{x}$ stretching vibrations observed in both $\mathrm{ZnO}$ and $\mathrm{ZnO}-\mathrm{NH}_{2}$ samples. A consequence of this reactive behaviour could also be partial dissolution of the zinc oxide surfaces, i.e. for both $\mathrm{ZnO}$ and $\mathrm{ZnO}-\mathrm{NH}_{2} \mathrm{NCs}$, as further reported below.

In EMEM, we hypothesize that the $\mathrm{ZnO}$ and $\mathrm{ZnO}-\mathrm{NH}_{2} \mathrm{NC}$ samples aggregate within a soft matrix of proteins and amino acids and all other biomolecules present in the serum, as already observed by FESEM. The gradual reduction of $-\mathrm{OH}$ group stretching could account for the interaction of these groups at the ZnO surface with the bound molecules. These behaviours can also be associated with the slight dissolution.

In contrast to the case of the pristine $\mathrm{ZnO}$ NCs and the $\mathrm{ZnO}-\mathrm{NH}_{2} \mathrm{NCs}$, a strong increase of the $-\mathrm{OH}$ stretching band from 3600 to $3200 \mathrm{~cm}^{-1}$ in the ZnO-DOPC NCs is observed (Fig. 7c). We attribute these variations to the physical adsorption and coordination with water molecules from both SBF and EMEM media on the phospholipidic layer, positively influencing the high colloidal stability of the ZnO-DOPC sample in waterbased media, in agreement with the DLS results of Fig. 5.

By comparing the X-ray diffraction patterns of the three $\mathrm{ZnO}$ nanocrystals before and after the biostability assays in both SBF and EMEM at different time steps (Fig. S6 in the ESI $\dagger$ ), one can notice a slight reduction of the diffraction intensities of the wurtzite reflections, i.e. (100), (002) and (101) peaks for both $\mathrm{ZnO}$ and $\mathrm{ZnO}-\mathrm{NH}_{2}$ NCs. Therefore, we can further support the previous FT-IR results assuming that partial, but not complete, hydrolysis and dissolution of the $\mathrm{ZnO}$ and $\mathrm{ZnO}-\mathrm{NH}_{2}$ surfaces takes place when they are in contact with SBF and EMEM. In some samples, we observed the appearance of sharp peaks at around $32^{\circ}$ attributed to $\mathrm{NaCl}$ crystals.

In contrast, the diffraction peaks of the ZnO-DOPC NCs after the different assay times did not decrease, owing to the high chemical stability of the sample and the maintenance of the initial crystalline structure.

As a further check of the crystalline quality of $\mathrm{ZnO}$, High Resolution Transmission Electron Microscopy (HR-TEM) was performed. In Fig. 9 and 10 we show a comparison of each NC structure before and after prolonged immersion ( 25 days) in either SBF or EMEM. All the pictures show the presence of singlecrystalline mono-domains, as confirmed by the Fast Fourier Transform (FFT) in the inset of the pictures, which refers to the white squared area. These data therefore suggest that the crystalline integrity of the three different nanocrystals is still preserved after prolonged immersion in different simulated and biological media. This result is not in contradiction with the previous FT-IR and XRD data, where only slight and partial dissolution was hypothesized.

In particular, the HR-TEM images of the ZnO-DOPC sample (especially in Fig. 10c, left panel) show the NCs immersed in an amorphous matrix. Considering that the sample was neither stained nor fixed for this imaging, this amorphous structure could be attributed to the phospholipidic shell.

The STEM images help to clarify the nanostructures' aggregation before and after the biostability treatments. Distinct nanocrystals 
(a)

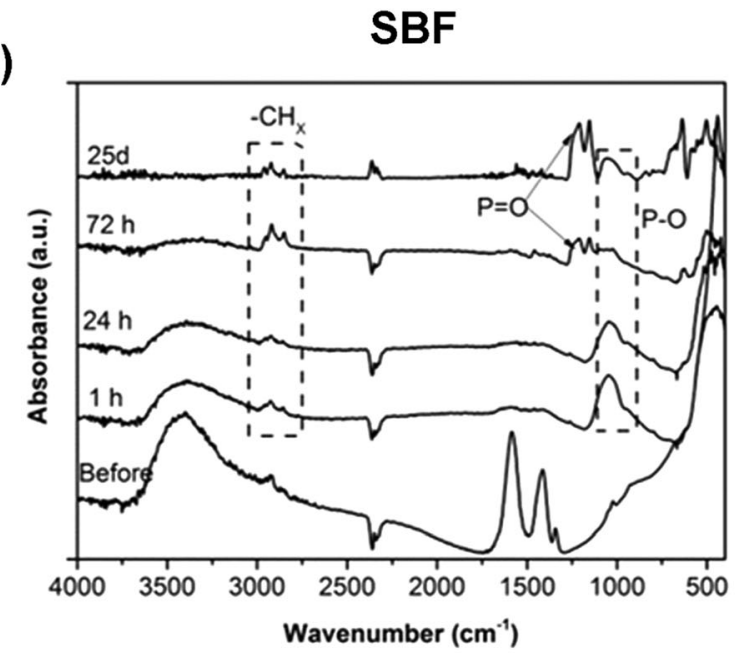

(b)

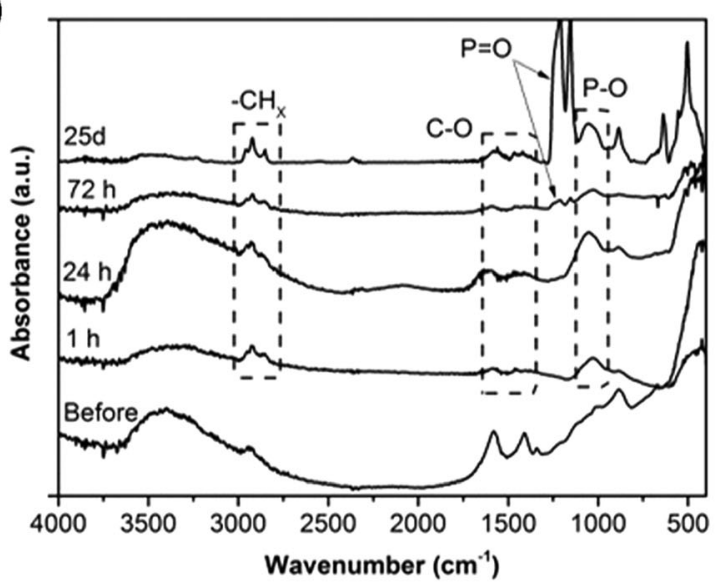

(c)

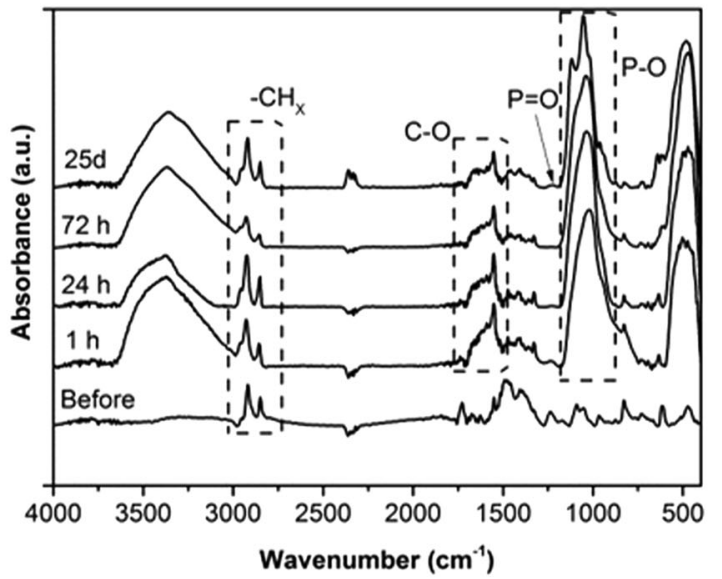

EMEM
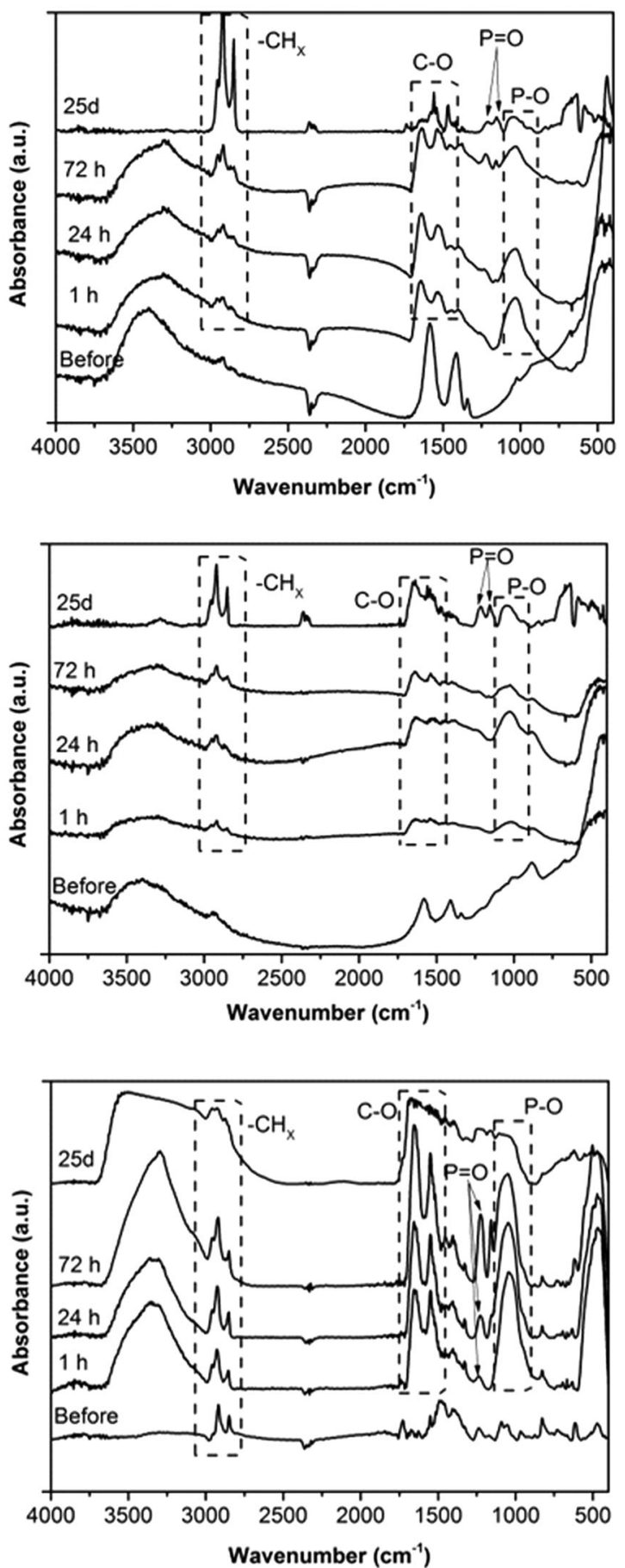

Fig. 7 Fourier-Transform InfraRed (FT-IR) spectra of the (a) pristine $\mathrm{ZnO} \mathrm{NCs}$, (b) ZnO- $\mathrm{NH}_{2} \mathrm{NCs}$, and (c) ZnO-DOPC NCs after different time steps of biostability assays in SBF (left) and EMEM (right).

are observed for all the three samples before biostability tests (Fig. 8a, 9a and 10a), whereas strong aggregation is visible in particular for the $\mathrm{ZnO} \mathrm{NC}$ samples (Fig. $8 \mathrm{~b}$ and c), and to a less extent for the $\mathrm{ZnO}-\mathrm{NH}_{2}$ samples (Fig. 9b and c), after 25 days in both SBF and EMEM. The as-prepared ZnO-DOPC is characterized by nanocrystals (Fig. 10a) that, still after 25 days of contact with simulated buffer and biological fluids, are embedded by a smooth matrix, attributed to the presence of phospholipids completely immersing the inorganic crystalline structure (see also Fig. S7 in the ESI $\dagger$ for other magnified STEM images). All the STEM measurements are in complete agreement with DLS and FESEM characterization.

ICP-MS analyses were also carried out on the SBF and EMEM solutions at each biostability time point, as reported in Fig. 11, 

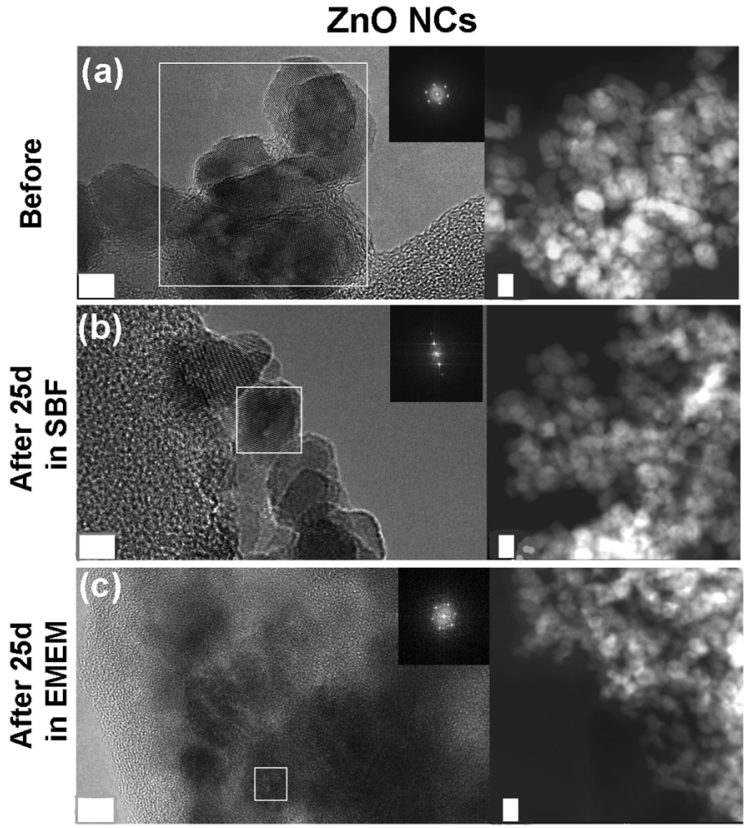

Fig. 8 HR-TEM, SAED and STEM imaging of the pristine $\mathrm{ZnO}$ nanocrystals: (a) before biostability treatments and in comparison after (b) 25 days in SBF solution and (c) 25 days in EMEM. The scale bar is $5 \mathrm{~nm}$.

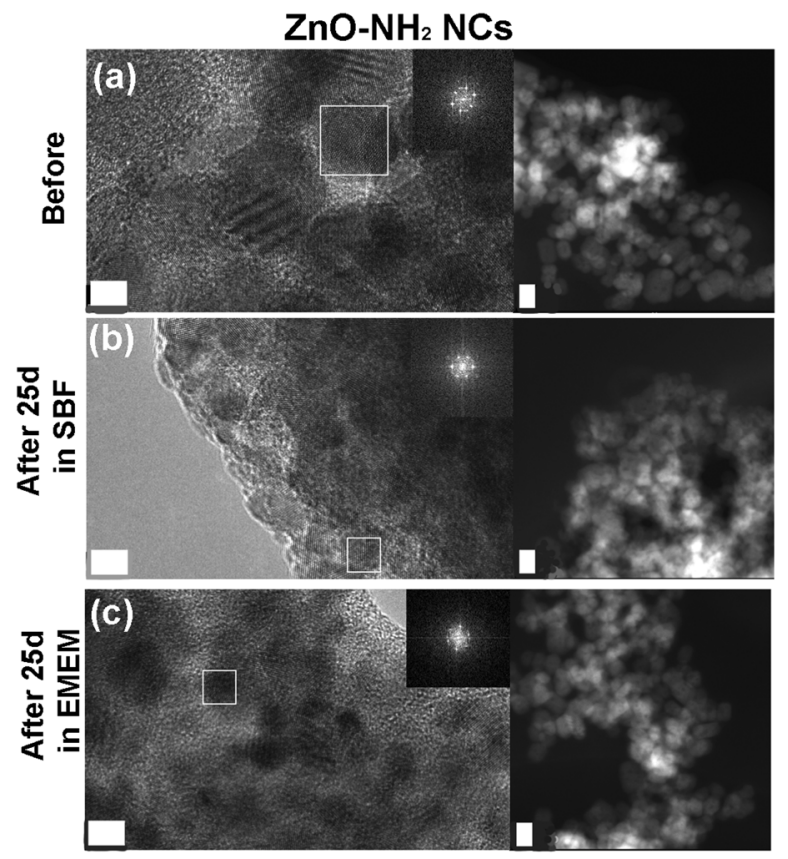

Fig. 9 HR-TEM, SAED and STEM imaging of the amine-functionalized $\mathrm{ZnO}-\mathrm{NH}_{2}$ nanocrystals: (a) before biostability treatments and in comparison after (b) 25 days in SBF solution and (c) 25 days in EMEM. The scale bar is $5 \mathrm{~nm}$.

monitoring the zinc, phosphorus and calcium elements, with the last two elements being highly reactive towards the ZnO surface. In SBF and EMEM solutions, for both $\mathrm{ZnO}$ and $\mathrm{ZnO}-\mathrm{NH}_{2}$ NCs, an increase of the $\mathrm{Zn}^{2+}$ cations is clearly observed in the first hour from 0 to a maximum of $180 \mathrm{ppm}$
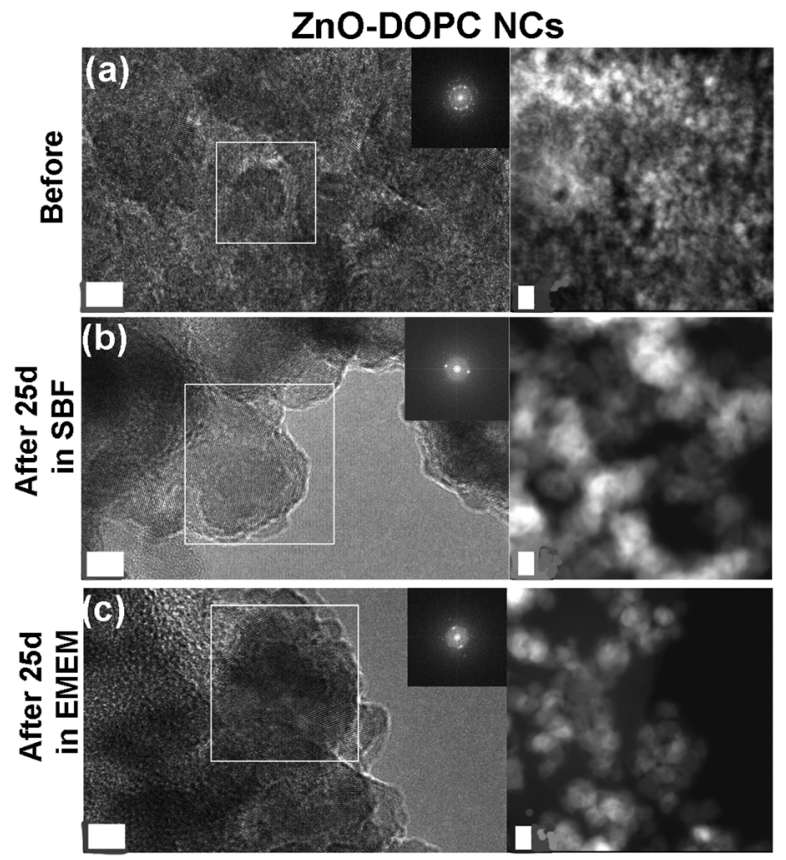

Fig. 10 HR-TEM, SAED and STEM imaging of the lipid-shielded ZnODOPC nanocrystals: (a) before biostability treatments and in comparison after (b) 25 days in SBF solution and (c) 25 days in EMEM. The scale bar is $5 \mathrm{~nm}$.
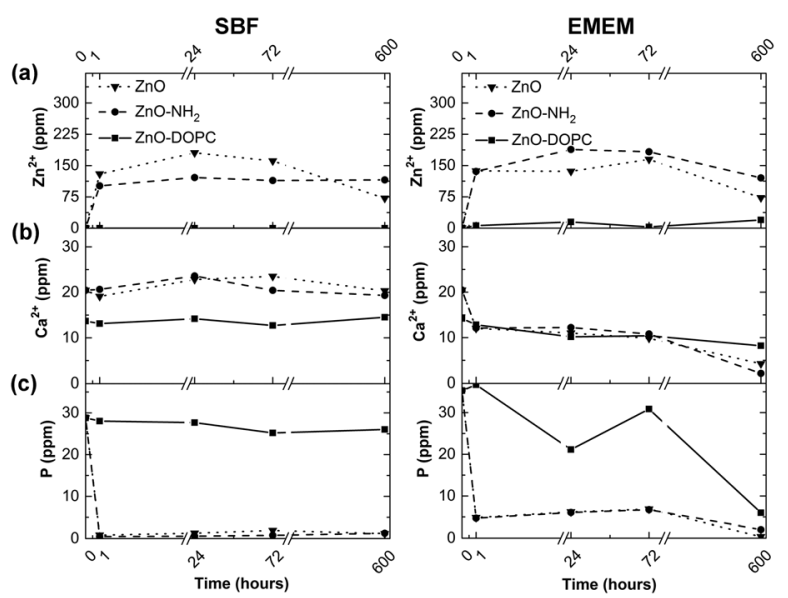

Fig. 11 ICP-MS analysis of (a) zinc, (b) calcium, and (c) phosphorus elements present in SBF and EMEM at different time steps of the biostability assays from the three $\mathrm{ZnO}$-based NCs.

for $\mathrm{ZnO}$ NCs and $121 \mathrm{ppm}$ for $\mathrm{ZnO}-\mathrm{NH}_{2}$ NCs in SBF and up to $165 \mathrm{ppm}$ for $\mathrm{ZnO} \mathrm{NCs}$ and $188 \mathrm{ppm}$ for $\mathrm{ZnO}-\mathrm{NH}_{2}$ NCs in EMEM. These amounts roughly correspond to a range of dissolution between 7.5 and $11 \mathrm{~mol} \%$ of zinc with respect to the initial amount of zinc from the NCs. These trends therefore underline the slight dissolution of these nanocrystalline structures in both media, confirming the FT-IR and XRD data reported above. In addition, a strong reduction of the phosphorus content is assessed from SBF (from $40 \mathrm{ppm}$ to $0.5 \mathrm{ppm}$ ) and a bit less in EMEM (from $40 \mathrm{ppm}$ to $10 \mathrm{ppm}$ ), confirming the precipitation of phosphate species on both $\mathrm{ZnO}$ and 
ZnO- $\mathrm{NH}_{2}$ sample surfaces already observed with EDS and FT-IR analyses. In contrast, the level of calcium cations does not change in SBF for the whole duration of the assays, which is also confirmed by the almost negligible presence of calciumcontaining species on the $\mathrm{ZnO}$ and $\mathrm{ZnO}-\mathrm{NH}_{2}$ surfaces in SBF, found in the previous FT-IR and EDS characterization. Literature studies report a high degree of interaction between the phosphate anions and $\mathrm{ZnO}$ nanoparticles. ${ }^{47}$ In silica or bioglass-based nanomaterial assays in SBF, co-precipitation of calcium cations with phosphate anions was observed leading to the formation of the hydroxyapatite compound on the material surfaces. ${ }^{48-50}$ However, we believe that in the present case, the strong interaction between zinc and phosphate is detrimental for the combination of such anions with $\mathrm{Ca}^{2+}$, and the sole precipitation of carbonate and phosphate groups on $\mathrm{ZnO}$ and $\mathrm{ZnO}-\mathrm{NH}_{2}$ NCs takes place. In addition, no evidence of hydroxyapatite can be observed (as reported in the X-ray diffractograms of Fig. S5, evidencing the only presence of ZnO-related wurtzite phase) in any of the three samples.

Differently, in EMEM the amount of calcium cations slowly decreases (from $15 \mathrm{ppm}$ to around $5 \mathrm{ppm}$ ) when in contact with the $\mathrm{ZnO}$ and $\mathrm{ZnO}-\mathrm{NH}_{2} \mathrm{NCs}$, in accordance with EDS analysis (Table S4, ESI $\dagger$ ) detecting the presence of calcium in all samples.

In remarkable contrast with the previous results, the composition of SBF and EMEM solutions in terms of phosphorus and calcium content does not vary significantly when in contact with the $\mathrm{ZnO}-\mathrm{DOPC}$ NCs. In particular, the presence of $\mathrm{Zn}^{2+}$ ions is almost not detectable in the used media for the whole assay time, i.e. until 25 days. This evidence confirms the previous results, showing no hydrolysis nor dissolution of the lipid-coated ZnO samples. An oscillating behaviour, with a
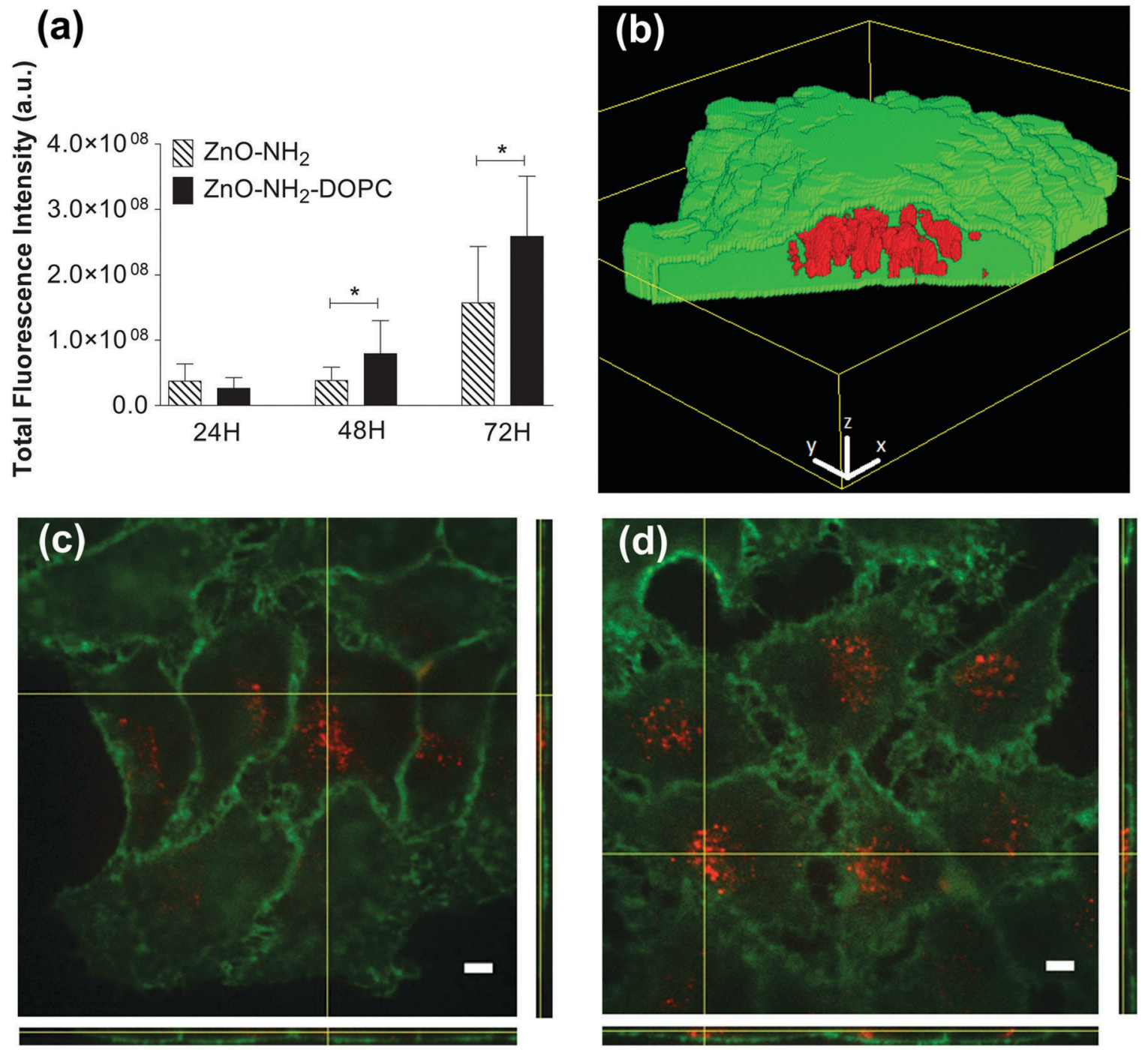

Fig. 12 (a) Fluorescence quantification of $\mathrm{ZnO}-\mathrm{NH}_{2}$ and $\mathrm{ZnO}-\mathrm{NH}_{2}-\mathrm{DOPC}$ nanocrystals in HeLa cells after 24, 48 and 72 hours incubation. Data are

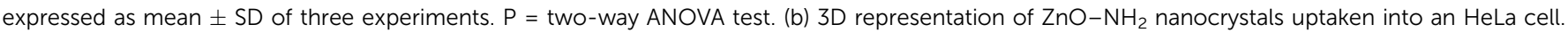
Intracellular NCs (in red) can be observed through the window opened in the cell membrane region (green). The z-stack images were processed with Particle_in_Cell-3D Macro. 3D scale bars $=3 \mu \mathrm{m}$. Representative fluorescent images of HeLa cell membranes (in green) incubated for 72 hours with fluorescent (c) $\mathrm{ZnO}-\mathrm{NH}_{2}$ and (d) $\mathrm{ZnO}-\mathrm{NH}_{2}-\mathrm{DOPC}$ nanocrystals (in red). Scale bars: $5 \mu \mathrm{m}$. 
tendency for reduction, can be just observed for the phosphorus content in EMEM for the ZnO-DOPC NCs. This behaviour is a clear proof of the precipitation of phosphate groups on this sample surface, as also previously confirmed by the FT-IR and EDS analysis.

All these findings support the idea that a phospholipidic shielding on the $\mathrm{ZnO}$ surface is very effective: (i) it enables the stabilization of the ZnO NCs as a colloidal suspension in different water and physiological media; (ii) it prevents their partial degradation, preserving the physico-chemical properties of the ZnO NCs; and (iii) most importantly, it avoids the release of potentially cytotoxic $\mathrm{Zn}^{2+}$ cations. In our opinion, these findings can be possible solely by the formation of a complete and dense coverage of the phospholipidic bilayer, selfassembled on the ZnO surface and able to prevent ZnO NCs' interactions with the surrounding medium.

\section{Internalization and cytotoxicity experiments in HeLa cells}

Several studies demonstrated that ZnO NCs' cytotoxicity and uptake efficacy are strictly influenced by nanocrystals' surface chemistry. ${ }^{19,51,52}$ To evaluate the effects of different surface functionalizations, the toxicity and cellular uptake of the pristine $\mathrm{ZnO}$ NCs and the functionalized ones were assessed on human epithelial carcinoma cells (HeLa). It is worth mentioning here that the methods used for these cellular studies impose the use of dye-labelled nanocrystals. As also reported in the Experimental section, we used the amine-functional group at the ZnO NC surface to covalently bind an ATTO-550 NHS ester dye. Therefore, any further comparison among the functionalized nanocrystals is performed between the $\mathrm{ZnO}-\mathrm{NH}_{2}$ and $\mathrm{ZnO}-\mathrm{NH}_{2}-\mathrm{DOPC}$.

The cellular uptake of HeLa cells treated with $18 \mu \mathrm{g} \mathrm{mL} \mathrm{m}^{-1}$ of ZnO- $\mathrm{NH}_{2}$ and $\mathrm{ZnO}-\mathrm{NH}_{2}-$ DOPC nanocrystals was qualitatively analysed based on fluorescence images after 24, 48 and 72 hours by Spinning Disk microscopy (Fig. 12). After 24 hours of incubation, the two different types of nanocrystals showed a comparable uptake rate. After longer incubation times (48 and 72 hours), the DOPC-coated NCs showed a statistically significant $(P<0.02)$ higher intensity of fluorescence possibly related to their higher internalization (Fig. 12d).

The effects of different concentrations of $\mathrm{ZnO}, \mathrm{ZnO}-\mathrm{NH}_{2}$ and $\mathrm{ZnO}-\mathrm{NH}_{2}-\mathrm{DOPC}$ nanocrystals on HeLa cell culture for 72 hours are shown in Fig. 13. From a quantitative point of view, these cytotoxicity data confirmed ZnO nanocrystals' toxic effect against HeLa cells only in the case of high $\mathrm{NC}$ concentration. ${ }^{53}$ Actually, the three kinds of ZnO NCs had no visible cytotoxic effect on HeLa cells after 72 hours treatment up to a concentration of about $18 \mu \mathrm{g} \mathrm{mL} \mathrm{m}^{-1}$. On the contrary, all of them showed a significant cytotoxic effect when used at concentrations as high as $90 \mu \mathrm{g} \mathrm{mL} L^{-1}$. The data trend of $\mathrm{ZnO}-\mathrm{NH}_{2}$ and $\mathrm{ZnO}-\mathrm{NH}_{2}$-DOPC NCs shows a significantly higher toxicity compared with the ZnO NCs' treatment, respectively at the concentrations of 36 and $18 \mu \mathrm{g} \mathrm{mL} \mathrm{m}^{-1}$. This enhanced cytotoxicity could be partially explained by their better dispersion in the biological medium compared to their unfunctionalized counterpart (as reported in the DLS results of Fig. 4). In this scenario, both $\mathrm{ZnO}-\mathrm{NH}_{2}$ and

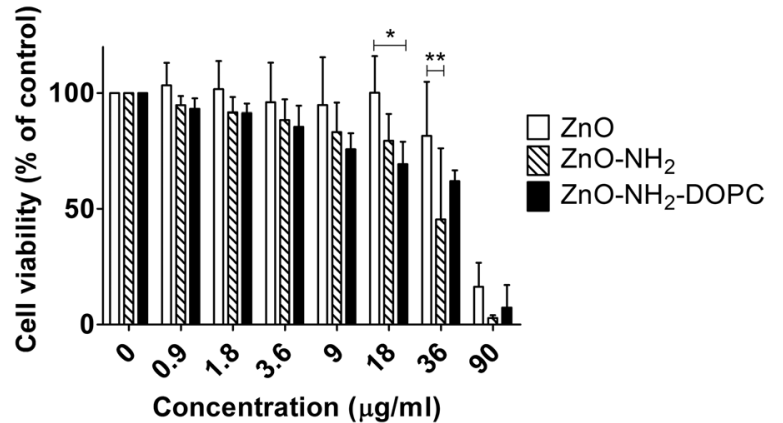

Fig. 13 Cell viability of HeLa cells after 72 hours exposure to $\mathrm{ZnO}, \mathrm{ZnO}-$ $\mathrm{NH}_{2}$ and $\mathrm{ZnO}-\mathrm{NH}_{2}-$ DOPC nanocrystals. The mitochondrial activity was measured with MTT assay and data were expressed as mean \pm SD of three experiments. ${ }^{*} p<0.05,{ }^{*} p<0.01$.

ZnO- $\mathrm{NH}_{2}$-DOPC NCs would be more easily uptaken by cancer cells.

In addition, our results suggest that the extent of internalization is not the only parameter affecting cell toxicity. After 72 hours of treatment, $\mathrm{ZnO}-\mathrm{NH}_{2}-\mathrm{DOPC}$ showed a greater degree of intracellular fluorescence compared to that of the aminopropyl functionalized $\mathrm{ZnO}-\mathrm{NH}_{2}$ NCs although the increased uptake was not associated to an enhanced cytotoxic effect. ${ }^{26}$

By considering all the previous results, these data confirm that intracellular release of zinc ions plays a key role in the definition of the cytotoxic effect, as already reported in the literature. ${ }^{40}$ Our results suggest that the presence of the lipidcoating limits the access of the ZnO NCs' surface to the lysosomal $\mathrm{pH}$, preventing metal ion dissolution. Consequently, the lipid-shell significantly reduces the cytotoxic effect on the cultured cell lines, despite the high internalization levels of the ZnO-DOPC NCs.

\section{Conclusions}

We have reported the biostability behaviour in simulated and biological media, as well as the cell internalization and cytotoxicity, of three different kinds of $\mathrm{ZnO}$ nanomaterials. In particular, pristine nanocrystals (ZnO NCs), amino-propyl functionalized $\mathrm{ZnO}-\mathrm{NH}_{2} \mathrm{NCs}$ and phospholipid-shielded $\mathrm{ZnO}-\mathrm{DOPC}$ NCs were studied. The results have shown an important effect of the surface chemistry and charge on the biostability behaviour at different time steps.

In particular, we have observed the strong aggregation and slight dissolution behaviour of both $\mathrm{ZnO}$ and $\mathrm{ZnO}-\mathrm{NH}_{2}$ NCs already at short time steps in water-based media, i.e. SBF, simulating the inorganic composition of human blood, and EMEM, the cell culture media.

In contrast, we have verified that the successful formation of a self-assembled phospholipid bilayer on the ZnO nanocrystals' surface leads to a more biostable nanoconstruct. Actually, the lipid-shell prevents NCs' aggregation in water-based media, improves the colloidal stability over time until 25 days and avoids NCs' dissolution into cytotoxic $\mathrm{Zn}^{2+}$ cations. This new 
formulation also improves the internalization of the nanocrystals into HeLa cancer cells. Strikingly, the higher level of internalization of $\mathrm{ZnO}-\mathrm{NH}_{2}-\mathrm{DOPC} \mathrm{NCs}$ compared to the uncoated $\mathrm{ZnO}-\mathrm{NH}_{2}$ counterpart is not reflected by a higher cytotoxic effect.

The above reported results give a clear insight into the behaviour of $\mathrm{ZnO}$ nanomaterials in biological media, indicating that an appropriate surface shielding, i.e. by a phospholipid bilayer, is fundamental to develop multifunctional ZnO NCs for therapeutic and bio-imaging applications in cancer cells.

\section{Conflicts of interest}

There are no conflicts of interest to declare.

\section{Acknowledgements}

This work has received funding from the European Research Council (ERC) under the European Union's Horizon 2020 research and innovation programme (grant agreement No. 678151 - Project Acronym “TROJANANOHORSE” - ERC starting Grant) and by a Regional program entitled "Attrarre Docenti di Qualità con Starting Grant” from the Compagnia di Sanpaolo, D. R. 349-2016. The help of Mr Mauro Raimondo in the acquisition of FESEM images and Ms Carla Celozzi and Mr Vanni Martignoni in ICP-MS analysis is gratefully acknowledged.

\section{References}

1 S. Stassi, A. Chiadò, V. Cauda, G. Palmara, G. Canavese, M. Laurenti and C. Ricciardi, Functionalized ZnO nanowires for microcantilever biosensors with enhanced binding capability, Anal. Bioanal. Chem., 2017, 409, 2615-2625.

2 M. Laurenti, S. Stassi, G. Canavese and V. Cauda, Surface Engineering of Nanostructured ZnO Surfaces, Adv. Mater. Interfaces, 2017, 4, 1600758.

3 M. Laurenti, A. Verna, M. Fontana, S. Stassi, G. Canavese, S. L. Marasso and V. Cauda, How Micropatterning and Surface Functionalization Affect the Wetting Behavior of ZnO Nanostructured Surfaces, Adv. Mater. Interfaces, 2016, 3, 1600110.

4 V. Cauda, P. Motto, D. Perrone, G. Piccinini and D. Demarchi, pH-triggered condduction of amine-functionalized single ZnO wire integrated on a customized nanogap electronic platform, Nanoscale Res. Lett., 2014, 9, 53.

5 X. Cao, X. Cao, H. Guo, T. Li, Y. Jie, N. Wang and Z. L. Wang, Piezotronic Effect Enhanced Label-Free Detection of DNA Using a Schottky-Contacted ZnO Nanowire Biosensor, ACS Nano, 2016, 10, 8038-8044.

6 P.-H. Yeh, Z. Li and Z. L. Wang, Schottky-Gated Probe-Free ZnO Nanowire Biosensor, Adv. Mater., 2009, 21, 4975-4978.

7 H.-M. Xiong, ZnO Nanoparticles Applied to Bioimaging and Drug Delivery, Adv. Mater., 2013, 25, 5329-5335.

8 H. Hong, J. Shi, Y. Yang, Y. Zhang, J. W. Engle, R. J. Nickles, $\mathrm{X}$. Wang and W. Cai, Cancer-Targeted Optical Imaging with
Fluorescent Zinc Oxide Nanowires, Nano Lett., 2011, 11, 3744-3750.

9 W. Song, J. Zhang, J. Guo, J. Zhang, F. Ding, L. Li and Z. Sun, Role of the dissolved zinc ion and reactive oxygen species in cytotoxicity of ZnO nanoparticles, Toxicol. Lett., 2010, 199, 389-397.

10 G. Applerot, A. Lipovsky, R. Dror, N. Perkas, Y. Nitzan, R. Lubart and A. Gedanken, Enhanced Antibacterial Activity of Nanocrystalline ZnO Due to Increased ROS-Mediated Cell Injury, Adv. Funct. Mater., 2009, 19, 842-852.

11 S. Nair, A. Sasidharan, V. V. Divya Rani, D. Menon, S. Nair, K. Manzoor and S. Raina, Role of size scale of ZnO nanoparticles and microparticles on toxicity toward bacteria and osteoblast cancer cells, J. Mater. Sci.: Mater. Med., 2009, 20, 235.

12 H. Yin and P. S. Casey, Effects of aspect ratio (AR) and specific surface area (SSA) on cytotoxicity and phototoxicity of ZnO nanomaterials, Chemosphere, 2015, 124, 116-121.

13 S. Stassi, V. Cauda, C. Ottone, A. Chiodoni, C. F. Pirri and G. Canavese, Flexible piezoelectric energy nanogenerator based on $\mathrm{ZnO}$ nanowires hosted in polycarbonate membrane, Nano Energy, 2015, 13, 474-481.

14 H. Yin, P. S. Casey, M. J. McCall and M. Fenech, Effects of Surface Chemistry on Cytotoxicity, Genotoxicity, and the Generation of Reactive Oxygen Species Induced by $\mathrm{ZnO}$ Nanoparticles, Langmuir, 2010, 26, 15399-15408.

15 A. Albanese, P. S. Tang and W. C. W. Chan, The Effect of Nanoparticle Size, Shape, and Surface Chemistry on Biological Systems, Annu. Rev. Biomed. Eng., 2012, 14, 1-16.

16 T. Xia, M. Kovochich, M. Liong, L. Madler, B. Gilbert, H. Shi, J. I. Yeh, J. I. Zink and A. E. Nel, Comparison of the Mechanism of Toxicity of Zinc Oxide and Cerium Oxide Nanoparticles Based on Dissolution and Oxidative Stress Properties, ACS Nano, 2008, 2, 2121-2134.

17 K. H. Muller, J. Kulkarni, M. Motskin, A. Goode, P. Winship, J. N. Skepper, M. P. Ryan and A. E. Porter, pH-Dependent Toxicity of High Aspect Ratio ZnO Nanowires in Macrophages Due to Intracellular Dissolution, ACS Nano, 2010, 4, 6767-6779.

18 F. Y. Qu and P. C. Morais, Energy levels in metal oxide semiconductor quantum dots in water-based colloids, J. Chem. Phys., 1999, 111, 8588-8594.

19 A. Punnoose, K. Dodge, J. W. Rasmussen, J. Chess, D. Wingett and C. Anders, Cytotoxicity of ZnO Nanoparticles Can Be Tailored by Modifying Their Surface Structure: A Green Chemistry Approach for Safer Nanomaterials, ACS Sustainable Chem. Eng., 2014, 2, 1666-1673.

20 A. Degen and M. Kosec, Effect of $\mathrm{pH}$ and impurities on the surface charge of zinc oxide in aqueous solution, J. Eur. Ceram. Soc., 2000, 20, 667-673.

21 R. G. Panchal, Novel therapeutic strategies to selectively kill cancer cells, Biochem. Pharmacol., 1998, 55, 247-252.

22 M. Abercrombie and E. J. Ambrose, The surface properties of cancer cells: a review, Cancer Res., 1962, 22, 525-548.

23 N. Papo, M. Shahar, L. Eisenbach and Y. Shai, A novel lytic peptide composed of DL-amino acids selectively kills cancer cells in culture and in mice, J. Biol. Chem., 2003, 278, 21018-21023. 
24 P. R. Leroueil, S. Hong, A. Mecke, J. R. Baker, B. G. Orr and M. M. Banaszak Holl, Nanoparticle Interaction with Biological Membranes: Does Nanotechnology present a Janus Face?, Acc. Chem. Res., 2007, 40, 335-342.

25 L. Zhang, Y. Jiang, Y. Ding, M. Povey and D. York, Investigation into the antibacterial behaviour of suspensions of $\mathrm{ZnO}$ nanoparticles (ZnO nanofluids), J. Nanopart. Res., 2007, 9, 479-489.

26 K. Zeng, J. Li, Z. Zhang, M. Yan, Y. Liao, X. Zhang and C. Zhao, Lipid-coated ZnO nanoparticles as lymphatic-targeted drug carriers: study on cell-specific toxicity in vitro and lymphatic targeting in vivo, J. Mater. Chem. B, 2015, 3, 5249-5260.

27 Y. Zhang, B. Newton, E. Lewis, P. P. Fu, R. Kafoury, P. C. Ray and $\mathrm{H}$. Yu, Cytotoxicity of organic surface coating agents used for nanoparticles synthesis and stability, Toxicol. In Vitro, 2015, 29, 762-768.

28 J. Sawai, S. Shoji, H. Igarashi, A. Hashimoto, T. Kokugan, M. Shimizu and H. Kojima, Hydrogen peroxide as an antibacterial factor in zinc oxide powder slurry, J. Ferment. Bioeng., 1998, 86, 521-522.

29 J. Sawai, E. Kawada, F. Kanou, H. Igarashi, A. Hashimoto, T. Kokugan and M. Shimizu, Detection of active oxygen generated from ceramic powders having antibacterial activity, J. Chem. Eng. Jpn., 1996, 29, 627-633.

30 V. Sharma, R. K. Shukla, N. Saxena, D. Parmar, M. Das and A. Dhawan, DNA damaging potential of zinc oxide nanoparticles in human epidermal cells, Toxicol. Lett., 2009, 185, 211-218.

31 S. W. Y. Wong, P. T. Y. Leung, A. B. Djurišić and K. M. Y. Leung, Toxicities of nano zinc oxide to five marine organisms: influences of aggregate size and ion solubility, Anal. Bioanal. Chem., 2010, 396, 609-618.

32 H. Yang, C. Liu, D. Yang, H. Zhang and Z. Xi, Comparative study of cytotoxicity, oxidative stress and genotoxicity induced by four typical nanomaterials: the role of particle size, shape and composition, J. Appl. Toxicol., 2009, 29, 69-78.

33 D. Xiaoyong, L. Qixia, C. Wenting, W. Yanli, W. Minghong, Z. Haijiao and J. Zheng, Nanosized zinc oxide particles induce neural stem cell apoptosis, Nanotechnology, 2009, 20, 115101.

34 T. Xia, M. Kovochich, M. Liong, L. Mädler, B. Gilbert, H. Shi, J. I. Yeh, J. I. Zink and A. E. Nel, Comparison of the Mechanism of Toxicity of Zinc Oxide and Cerium Oxide Nanoparticles Based on Dissolution and Oxidative Stress Properties, ACS Nano, 2008, 2, 2121-2134.

35 S. George, S. Pokhrel, T. Xia, B. Gilbert, Z. Ji, M. Schowalter, A. Rosenauer, R. Damoiseaux, K. A. Bradley, L. Mädler and A. E. Nel, Use of a Rapid Cytotoxicity Screening Approach To Engineer a Safer Zinc Oxide Nanoparticle through Iron Doping, ACS Nano, 2010, 4, 15-29.

36 Z. Yang and C. Xie, Zn2+ release from zinc and zinc oxide particles in simulated uterine solution, Colloids Surf., B, 2006, 47, 140-145.

37 P. J. Moos, K. Chung, D. Woessner, M. Honeggar, N. S. Cutler and J. M. Veranth, ZnO Particulate Matter Requires Cell Contact for Toxicity in Human Colon Cancer Cells, Chem. Res. Toxicol., 2010, 23, 733-739.

38 B. N. Feltis, S. J. O'Keefe, A. J. Harford, T. J. Piva, T. W. Turney and P. F. A. Wright, Independent cytotoxic and inflammatory responses to zinc oxide nanoparticles in human monocytes and macrophages, Nanotoxicology, 2012, 6, 757-765.

39 M. Xu, J. Li, N. Hanagata, H. Su, H. Chen and D. Fujita, Challenge to assess the toxic contribution of metal cation released from nanomaterials for nanotoxicology - the case of ZnO nanoparticles, Nanoscale, 2013, 5, 4763-4769.

40 C. Shen, S. A. James, M. D. de Jonge, T. W. Turney, P. F. A. Wright and B. N. Feltis, Relating Cytotoxicity, Zinc Ions, and Reactive Oxygen in ZnO Nanoparticle-Exposed Human Immune Cells, Toxicol. Sci., 2013, 136, 120-130.

41 J. W. Rasmussen, E. Martinez, P. Louka and D. G. Wingett, Zinc oxide nanoparticles for selective destruction of tumor cells and potential for drug delivery applications, Expert Opin. Drug Delivery, 2010, 7, 1063-1077.

42 A. A. Torrano, J. Blechinger, C. Osseforth, C. Argyo, A. Reller, T. Bein, J. Michaelis and C. Bräuchle, A fast analysis method to quantify nanoparticle uptake on a single cell level, Nanomedicine, 2013, 8, 1815-1828.

43 C. Pacholski, A. Kornowski and H. Weller, Self-Assembly of ZnO: From Nanodots to Nanorods, Angew. Chem., Int. Ed., 2002, 41, 1188-1191.

44 V. Cauda, H. Engelke, A. Sauer, D. Arcizet, C. Bräuchle, J. Rädler and T. Bein, Colchicine-Loaded Lipid BilayerCoated $50 \mathrm{~nm}$ Mesoporous Nanoparticles Efficiently Induce Microtubule Depolymerization upon Cell Uptake, Nano Lett., 2010, 10, 2484-2492.

45 A. O. Hohner, M. P. C. David and J. O. Rädlera, Controlled solvent-exchange deposition of phospholipid membranes onto solid surfaces, Biointerphases, 2010, 5, 1-8.

46 V. Cauda, C. Argyo, D. G. Piercey and T. Bein, "Liquid-Phase Calcination" of Colloidal Mesoporous Silica Nanoparticles in High-Boiling Solvents, J. Am. Chem. Soc., 2011, 133, 6484-6486.

47 R. Herrmann, F. J. García-García and A. Reller, Rapid degradation of zinc oxide nanoparticles by phosphate ions, Beilstein J. Nanotechnol., 2014, 5, 2007-2015.

48 V. Cauda, A. Schlossbauer and T. Bein, Bio-degradation study of colloidal mesoporous silica nanoparticles: Effect of surface functionalization with organo-silanes and poly(ethylene glycol), Microporous Mesoporous Mater., 2010, 132, 60-71.

49 V. Cauda, B. Onida, B. Platschek, L. Mühlstein and T. Bein, Large antibiotic molecule diffusion in confined mesoporous silica with controlled morphology, J. Mater. Chem., 2008, 18, 5888-5899.

50 V. Cauda, L. Mühlstein, B. Onida and T. Bein, Tuning drug uptake and release rates through different morphologies and pore diameters of confined mesoporous silica, Microporous Mesoporous Mater., 2009, 118, 435-442.

51 M. Altunbek, A. Baysal and M. Çulha, Influence of surface properties of zinc oxide nanoparticles on their cytotoxicity, Colloids Surf., B, 2014, 121, 106-113.

52 J. Liu, X. Feng, L. Wei, L. Chen, B. Song and L. Shao, The toxicology of ion-shedding zinc oxide nanoparticles, Crit. Rev. Toxicol., 2016, 46, 348-384.

53 M. Pandurangan, G. Enkhtaivan and D. H. Kim, Anticancer studies of synthesized $\mathrm{ZnO}$ nanoparticles against human cervical carcinoma cells, J. Photochem. Photobiol., B, 2016, 158, 206-211. 